\title{
New material of Alierasaurus ronchii (Synapsida, Caseidae) from the Permian of Sardinia (Italy), and its phylogenetic affinities
}

\author{
Marco Romano, Ausonio Ronchi, Simone Maganuco, and Umberto Nicosia
}

\begin{abstract}
New characters of the giant caseid Alierasaurus ronchii are described here based on material recovered from the type locality in the Permian deposits of Cala del Vino Formation (Sardinia NW) and additional preparation of the previously collected material. All new described osteological elements are characterized by the same state of preservation and, given the absence of double elements and the total compatibility in absolute size, the new material can be attributed without doubt to the holotypic individual of $A$. ronchii. Highly diagnostic material includes a caudal neural spine with a broad bifid distal termination. This represents a synapomorphy characterizing the more derived caseids, thus fully confirming the attribution of the Sardinian specimen to Caseidae. Also the other vertebral material and newly collected ribs show a typical caseid structure, fully consistent with the previously published material. Despite the highly partial nature of Alierasaurus, the taxon was included in a recent phylogenetic analysis of caseids to investigate its phylogenetic position within the monophyletic Caseasauria. Alierasaurus falls as the sister taxon of Cotylorhynchus, and is autapomorphic in the general construction of MT-IV and proximal phalanx IV-I. The absolute size of the newly recovered material confirms a gigantic body size for Alierasaurus, comparable, if not greater, to that of the huge North American species Cotylorhynchus hancocki (up to $6 \mathrm{~m}$ in length). Such gigantic adult body size, closely correlated to its herbivorous lifestyle, must have been selected during evolution of caseids, leading to substantial advantages in terms of fitness.
\end{abstract}

Marco Romano. Museum für Naturkunde, Leibniz-Institut für Evolutions- und Biodiversitätsforschung, Invalidenstrasse 43, Berlin, Germany; Dipartimento di Scienze della Terra, "Sapienza" Universita` di Roma, P.le A. Moro 5, 00185 Rome, Italy. marco.romano@mfn-berlin.de

Ausonio Ronchi. Dipartimento di Scienze della Terra, Università di Pavia, v. Ferrata 1, 27100 Pavia, Italy. ausonio.ronchi@unipv.it

Simone Maganuco. Museo di Storia Naturale di Milano, Corso Venezia 55, 20121 Milano, Italy. simonemaganuco@iol.it

Umberto Nicosia. Dipartimento di Scienze della Terra, "Sapienza" Universita` di Roma, P.le A. Moro 5, 00185 Rome, Italy. umberto.nicosia@uniroma1.it

Romano, Marco, Ronchi, Ausonio, Maganuco, Simone, and Nicosia, Umberto. 2017. New material of Alierasaurus ronchii (Synapsida, Caseidae) from the Permian of Sardinia (Italy), and its phylogenetic affinities. Palaeontologia Electronica 20.2.26A: 1-27

palaeo-electronica.org/content/2017/1889-new-material-of-alierasaurus

Copyright: ( ) June 2017 Society of Vertebrate Paleontology. This is an open access article distributed under the terms of the Creative Commons Attribution License, which permits unrestricted use, distribution, and reproduction in any medium, provided the original author and source are credited.

creativecommons.org/licenses/by/4.0/ 
Keywords: Non-therapsid Synapsids; Caseasauria; Caseidae; Permian; Italy; Phylogeny

Submission: 19 May 2016 Acceptance: 30 May 2017

\section{INTRODUCTION}

Caseid synapsids are a highly interesting group of fossil vertebrate in part because of their ambiguous evolutionary history. Caseids, together with the varanopids, represent one of two primitive clades that co-exist with the more derived therapsid synapsids (Dilkes and Reisz, 1996; Reisz and Laurin, 2001; Maddin et al., 2008; Reisz and Fröbisch, 2014). The youngest known occurrence of caseids may be represented by a still undescribed large caseid from the La Lieude Formation of the Lodève Basin, a rock unit tentatively assigned to an early Lopingian age by some authors (Schneider et al., 2006; Lopez et al., 2008) while other authors ascribe this formation to the Wordian (Gand and Durand, 2006; Michel et al., 2015).

There has been a renewed interest in the Caseasauria and caseids stemming from new analyses of historical material and the description of new taxa (e.g., Romano and Nicosia, 2015; Brocklehurst et al., 2016; Romano, 2017a). Reisz (2005) described the small caseid Oromycter dolesorum from the Lower Permian deposits in the Dolese Quarry (Richards Spur, Oklahoma), representing, at that time, the most basal member of the clade. According to Reisz, the occurrence of this small caseid in upland environment indicates that the initial evolutionary history of this group of synapsids could have occurred far from the typical floodplain depositional environments inhabited by more derived species.

Maddin et al. (2008) re-described in detail the cranial material of Ennatosaurus tecton from the Middle Permian of Russia, performing the first 'modern' cladistic analysis of Caseidae. The analysis confirmed the basal position of Oromycter within caseids, and suggested the paraphyly of the genus Casea, with 'Casea' rutena being the sister taxon of the clade made by E. tecton, Cotylorhynchus romeri, and Angelosaurus dolani. The obtained phylogenetic hypothesis resolved in a relatively long ghost lineage, at least 10 million years, for Ennatosaurus tecton, representing the sister group of $C$. romeri $+A$. dolani (according to the obtained topology the divergence of the lineage leading to the Russian caseid must have occurred during the Early Permian).
Reisz et al. (2009) conducted a cladistic analysis to determine the phylogenetic position of the Eothyrididae Eothyris and Oedaleops, highlighting a number of cranial characters that make this clade as a better representative of the primitive synapsid cranial morphotype with respect to ophiacodontids. The analysis confirmed the monophyly of the Eothyrididae and of Caseasauria as well, with Eothyrididae forming the sister taxon of the more diversified and younger Caseidae.

Reisz et al. (2011) described the large caseid Ruthenosaurus russellorum from the Early Permian (upper Cisuralian to lower Lopingian) of the Rodez Basin, France. Although being an immature individual, $R$. russellorum is characterized by several autapomorphies in the post-cranium which justify the validity of a new taxon. Furthermore, based on the topology provided by Maddin et al. (2008), Reisz et al. (2011) moved 'Casea' rutena to the new genus Euromycter, with the new combination E. rutenus.

Ronchi et al. (2011) and Romano and Nicosia (2014) described the first skeletal material referable to non-therapsid synapsid from Italy, the caseid Alierasaurus ronchii from the Permian Cala del Vino Formation (Alghero, Nurra, northwest Sardinia). The taxon is known on the basis of partial but diagnostic postcranial material, including vertebrae, ribs, and peculiar autopod elements.

Benson (2012) conducted a phylogenetic analysis of basal synapsids including a high number of postcranial characters. Although cranial characters support the traditional conception of Caseasauria as the most basal clade within nontherapsid synapsids, the postcranial ones and the full dataset lead the clade of Ophiacodontidae +Varanopidae to occupy this basal position. With respect to the work by Maddin et al. (2008), Benson (2012) included for the first time in the cladistic analysis the taxa Angelosaurus romeri, Caseopsis agilis, Cotylorhynchus bransoni, Cotylorhynchus hancocki, and Trichasaurus texensis (the latter alternatively attributed to caseids, edaphosaurids, or to "Pelycosauria" incertae sedis; see Romano and Nicosia [2015] and references therein for a detailed overview).

LeBlanc and Reisz (2014) described a new specimen of Casea broilii that preserves the pelvic, hind limb, and sacral regions in three dimensions, 
and discussed in detail the early stages in the evolution of the sacrum in the basal synapsid lineage that led to mammals. Reisz and Fröbisch (2014) described the small taxon Eocasea martini, considered today as the oldest (late Pennsylvanian of Kansas, USA), thus shedding light on the evolutionary gap in the history of the family, starting from the basal separation from the eothyridids. The newly described taxon is crucial in showing that the large herbivorous caseids evolved from small, nonherbivorous taxa.

Sacchi et al. (2014) in discussing the new ichnotaxon Dimetropus osageorum from the Early Permian of Oklahoma (USA) found a very good correspondence between the overall morphology of footprints ("footprint holomorphy" sensu Romano et al., 2016) and the foot structure in large caseids, making it a very compelling attribution to the Caseasauria (even if a large edaphosaurid cannot be excluded a priori).

Romano and Nicosia (2015) conducted a phylogenetic analysis of Caseidae including for the first time the fragmentary taxa 'Casea' nicholsi and Caseoides sanangeloensis. The general topology was largely consistent with the results of Maddin et al. (2008) and Benson (2012), with issues still to be discussed and resolved such as the position of 'Casea' halselli and Trichasaurus (the latter considered a caseid in Benson, 2012) falling outside caseids, and 'Casea' nicholsi making once again the genus Casea paraphyletic, forming a sister group with Caseopsis agilis. Taking into account the position assumed by 'Casea' halselli in the topology and the very fragmentary nature of the holotype (FMNH UR 117), Romano and Nicosia (2015) regarded this species as nomen dubium.

Spindler et al. (2016) have re-interpreted the two historical fossil Callibrachion gaudryi (Artinskian of France) and Datheosaurus macrourus (Gzhelian of Poland) as basal caseasaurs, previously ascribed to haptodontine-grade sphenacodontians or treated as nomina dubia. According to the authors, Datheosaurus could be referred to Eothyrididae or represents a basal caseid, while Callibrachion seems to share several features with the genus Casea. The authors concluded that there are not enough characters to conduct a phylogenetic analysis including the two taxa, however the new re-description and taxonomic attribution contributes to further shrink the ghost lineage at the base of Caseasauria.

Caseids are among the five clades that within the late Pennsylvanian-Cisuralian interval independently evolved the capacity to process high- fiber plant material (see Olson, 1968; Reisz and Sues, 2000; Romano, 2017b). Along with caseids, there are edaphosaurids (Synapsida, with Edaphosaurus novomexicanus from the Permo-Carboniferous of New Mexico, representing the oldest known herbivorous edaphosaur; see Modesto and Reisz, 1992), diadectid cotylosaurs (the oldest known herbivorous diadectid is Diasparactus zenos, from the Upper Pennsylvanian of the Ada Formation of Seminole County, Oklahoma; see Kissel and Lehman, 2002), captorhinid and bolosaurid reptiles. In the latter group, herbivory appears with a substantial delay compared to synapsids and to diadectids, being reported for the first time in Labidosaurikos meachami from the Lower Permian of Oklahoma (Dodick and Modesto, 1995) and in Captorhinikos valensis from contemporaneous strata of Texas (Modesto et al., 2014).

The new material described from the Permian deposits of Cala del Vino (Torre del Porticciolo Promontory, Sardinia NW) is of great importance in understanding the evolution of herbivory. Our study shows the achievement of colossal size in these herbivores, presumably as a physiological response to the new type of diet and metabolism.

\section{MATERIAL AND METHODS}

All the new recovered material comes from the mid- to upper levels of the Permian Cala del Vino Formation (Torre del Porticciolo promontory, about $13 \mathrm{~km}$ northeast of Alghero, Sardinia NW), collected in the same sedimentary body in which the holotype of $A$. ronchii was found. The newly recovered bones lay completely embedded and isolated in the sediment, thus confirming the previous taphonomic interpretation reported in Ronchi et al. (2011). Bones size and preservation, as well as the absence of double and repeated elements, allows us to refer with confidence all new material to the same individual of Alierasaurus ronchii. As already discussed in Ronchi et al. (2011) and Romano and Nicosia (2014) the preserved bone are frequently characterized by several tubercles, scattered on the surface. To understand whether these tubercles are made of bone or simply represent metallic incrustations, a phalanx and rib portion with tubercles were analyzed at CT-Scan, in the facilities of the Museum für Naturkunde in Berlin. The specimens were scanned using X-ray computed tomography (phoenix|x-ray nanotom $s$ ) at $110 \mathrm{kV}, 190 \mu \mathrm{A}$ for $1400 / 360^{\circ}$ projections / segment of the multiscan, and an exposition timing of $750 \mathrm{~ms} /$ projection. The specimen was scanned at a magnification ratio of $x 1.54100859$, and an 

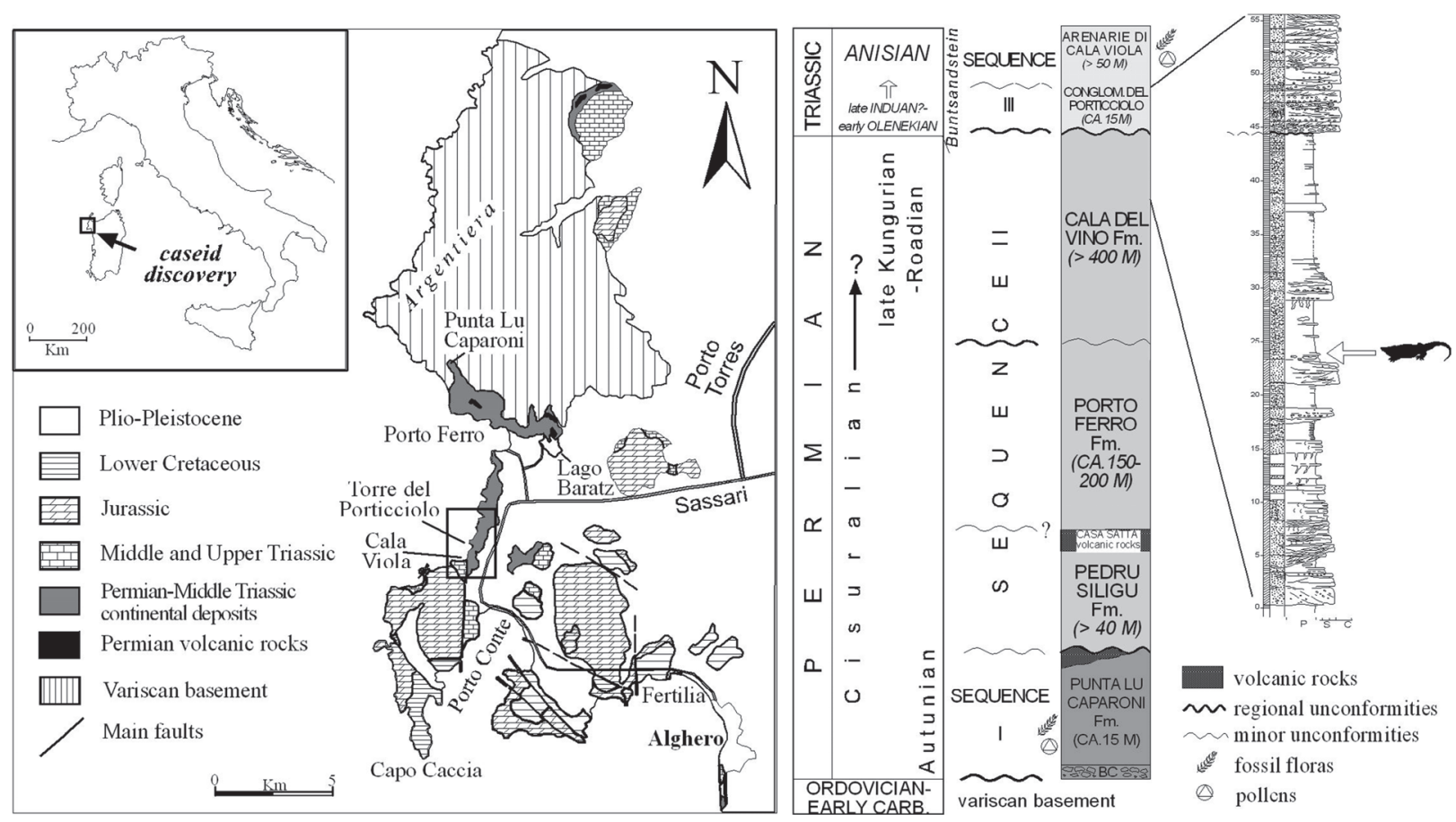

FIGURE 1. Discovery location and stratigraphic position of Alierasaurus ronchii in the frame of the Permian and Triassic succession of Nurra (NW Sardinia, Italy).

effective voxel size of $0.03244628 \mathrm{~mm}$ as well as an additional calibration value of 1.313 . The analysis revealed that the tubercles are made entirely of bone, while some polymetallic crusts were deposited in bone fractures. Some images from the CTscan and a brief discussion is provided in Appendix 1.

The new material was prepared in the laboratories of Dipartimento di Scienze della Terra, "Sapienza" Università di Roma. Each single bone was prepared, consolidated, and photographed according to principal views. Three-dimensional models of rib NS 151/76 in its original strike and dip position were obtained through photogrammetry, using photographs taken soon after the discovery. Photographs have been acquired with a 10.5 Megapixel Canon EOS 400D with $18 \mathrm{~mm}$ focal length and the 3D models were obtained using the free software Arc 3D, a web tool for Remote 3D reconstruction (see Cipriani et al., 2016), and MeshLab which allows to 'clean up' the imperfections of the obtained model, to cover with a interpolating surface any holes in the mesh, and to delete unnecessary portions.

A cladistic analysis was conducted to assess the phylogenetic position of Alierasaurus within Caseasauria. For the analysis the data matrix and characters used in Romano and Nicosia (2015) were considered with the addition of five continu- ous morphometric characters, built on the fourth metatarsal and proximal phalanx IV-I (see Appendix 2) and scored with the gap-weighting method by Thiele (1993; see Romano and Nicosia, 2015).

\section{Institutional Abbreviations}

FMNH, Field Museum of Natural History, Chicago, Illinois, U.S.A.; MPUR NS, Museum of Paleontology, University of Rome, Rome, Italy, New Series; OMNH, Sam Noble Oklahoma Museum of Natural History, University of Oklahoma, Norman, Oklahoma, U.S.A. MSNM, Museo di Storia Naturale di Milano, Milano Italy.

\section{Geological Setting}

Alierasaurus ronchii was found at the top of the Permian succession in Nurra (NW Sardinia). Such continental Late Paleozoic sequence here cropping out, is wonderfully exposed along the coast North of Capo Caccia Mesozoic promontory and represents a reference section for the whole peri-Tethyan domain (Figure 1).

Since the first half of the twentieth century many authors debated at length about the ageattribution of the different sedimentary units, which compose the up to 600-m-thick basin-fill (see Cassinis et al., 2000). Recently, the whole sedimentary succession has been conveniently subdivided into three main tectonosedimentary units (TSUn) (Cas- 
sinis and Ronchi, 2002; Cassinis et al., 2003; Ronchi et al., 2008; Cassinis et al., 2012). The first TSU1 is late Autunian in age, and is mainly composed of generally fine-grained alluvial to lacustrine clastic sediments and widespread calcalkaline acidic to intermediate effusive products. An intermediate cycle (TSU2), mostly made up of fluvial detritic red beds, is marked at its base by a stratigraphical discontinuity. It is composed by a group of formations (from base to top, namely, Pedru Siligu Fm., Porto Ferro Fm. and Cala del Vino Fm.) whose age spans from the middle Cisuralian to the early Guadalupian (Ronchi et al., 2011). The third cycle (TSU3) consists of Lower to Middle Triassic red clastics, stratigraphically correlated to the Germanic Buntsandstein (Cassinis et al., 2003).

The Cala del Vino Formation (CdV), which has yielded the caseid remains, overlies with a clear angular unconformity with the previous unit. This unit crops out continuously along the coast from Cala Viola to Porto Ferro, with an estimated thickness of $400 \mathrm{~m}$. These continental deposits are represented by an alternation of gray-green sand bodies with lateral accretion and overbank alluvial plain wine-red fines, typical of a meandering river settings. The different lithofacies of the $\mathrm{CdV}$ yield many invertebrate burrows and tracks that helped in the palaeoenvironmental reconstruction across the PT boundary (Baucon et al., 2014).

\section{SYSTEMATIC PALAEONTOLOGY}

\author{
Subclass SYNAPSIDA Osborn, 1903 \\ Suborder CASEASAURIA Williston, 1912 \\ Family CASEIDAE Williston, 1911 \\ Genus ALIERASAURUS Romano and Nicosia, \\ 2014
}

Type species. Alierasaurus ronchii Romano and Nicosia, 2014

Alierasaurus ronchii Romano and Nicosia, 2014 Figures 2-8

Revised diagnosis. Very large caseid with an overall size comparable or greater than Cotylorhynchus hancocki, and characterized by the following autapomorphies: metatarsal IV with distinct axial region, length about twice that of the corresponding proximal phalanx, not short and massive as in other large caseids; metatarsal IV proximal head not orthogonal to the bone axis, forming an angle of $120^{\circ}$ with the shaft: with this conformation, the proximal and distal heads are much closer along the medial side of the metatarsal; clawshaped ungual phalanges proportionally shorter than in Cotylorhynchus, with a double ventral flexor tubercle very close to the proximal rim of the phalanx; ungual phalangeal axis bent downward and medially; distal transverse section subtriangular, not spatulate as in Cotylorhynchus. Ventrodistal orientation of the phalangeal distal articular surface (synapomorphy of Caseasauria); sacral and dorsal neural spines with a transversely expanded dorsal tip, forming a spine table (synapomorphy of caseids more derived than Casea broilii).

New described material. NS 151/7, NS 151/8, NS151/9, NS151/10, NS151/11, NS151/12, NS 151/33 (caudal vertebrae); NS 151/15, NS 151/ $16 A$, NS 151/16B, NS 151/17, NS151/18, NS 151/ 29 , NS 151/30 (isolated zygapophyses); NS 151/ 48, NS 151/74 (isolated neural spines); NS 151/59, NS 151/72 (partial haemal arches); NS 151/39, NS $151 / 40$, NS $151 / 42$, NS $151 / 54$ and NS $151 / 55$, NS $151 / 75$, NS 151/76 (dorsal ribs).

\section{Description}

Vertebrae. Specimen NS151/10 is the largest caudal vertebra among those recovered to date, thus representing the most anterior one (Figure 2.1-4). The specimen is fairly laterally compressed, with the centrum sub-elliptical in shape. The left side, probably exposed for a certain period to the erosion, looks damaged and eroded so that it exposes the notochordal portion of the centrum. The left side of the centrum, the left pedicel and consequently also the left prezygapophysis are missing, probably due to breakage. The better preserved right side shows a centrum markedly depressed in the lateral portion, rimmed by stout lips, strongly bent inwards. Anterior and posterior lips have an average thickness of about $1 \mathrm{~cm}$; this value seems to not vary significantly throughout the perimeter of the centrum. The latter has a length, measured along the ventral border, of about $5 \mathrm{~cm}$, while along the dorsal one measures about $5.5 \mathrm{~cm}$; its height is estimated at about $6.5 \mathrm{~cm}$. The interruption of the notochordal canal occurs at a depth of about $2 \mathrm{~cm}$ on the anterior side and of about $3 \mathrm{~cm}$ on the posterior side. On the ventral side, the centrum being incomplete makes it impossible to observe the presence of the characteristic longitudinal groove seen in other caseids (see Romano and Nicosia, 2014). The vertebra total height, measured from the ventral edge of the centrum to the base of the neural spine, is about $15 \mathrm{~cm}$. Due to the substantial compression, the right prezygapophysis shows an upwards rotation of about $90^{\circ}$. Consequently, the neural arch is fairly flattened and stretched upward. The only articular facet that is visible is that on the 

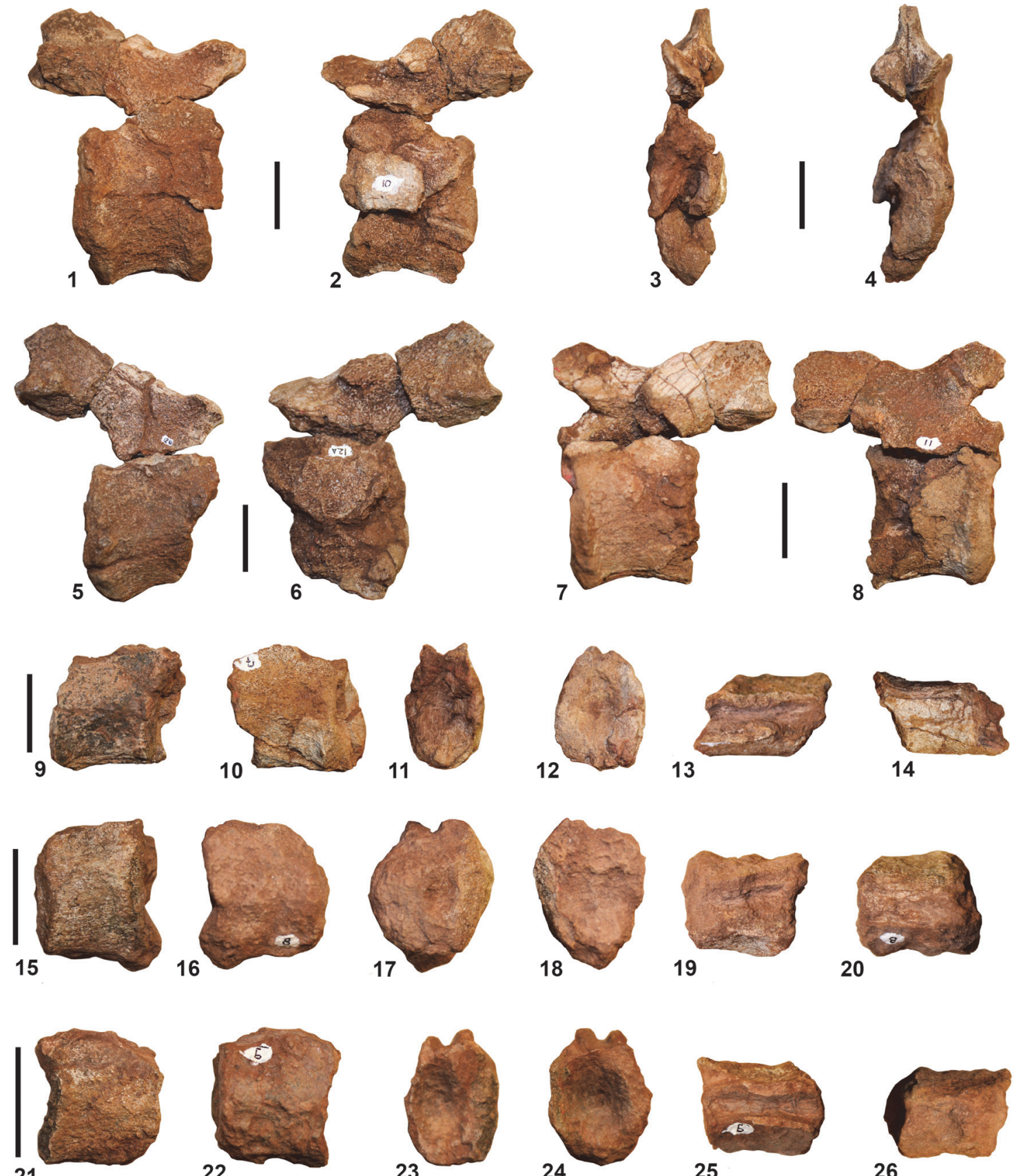

25
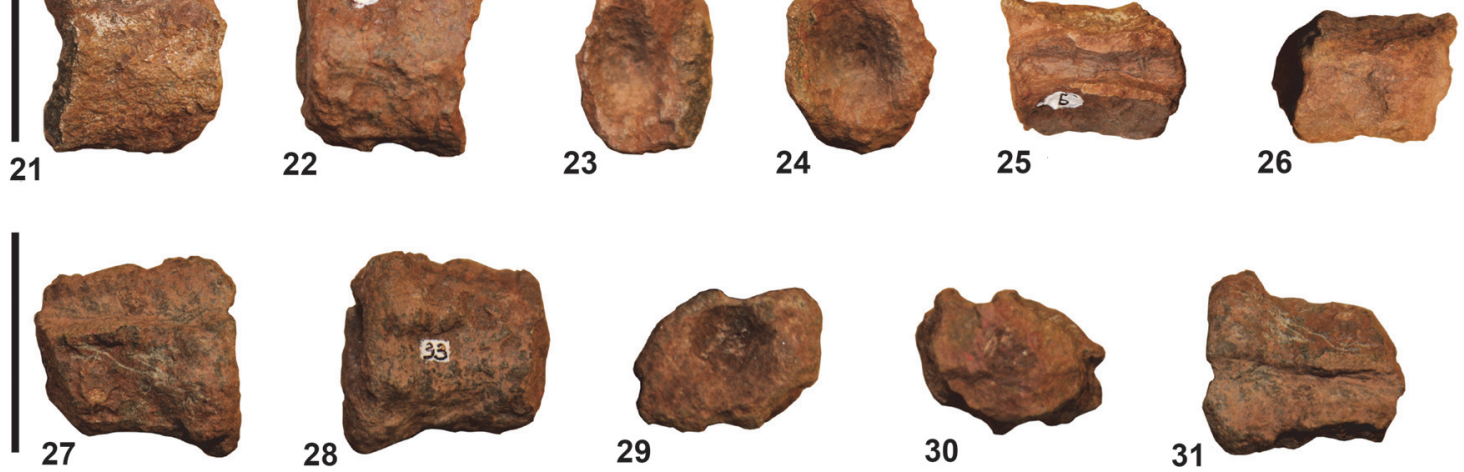

FIGURE 2. New recovered vertebral material of Alierasaurus ronchii in lateral $(1,2,5-8,9,10,15,16,21,22,27,28)$, anterior and posterior $(3,4,11,12,17,18,23,24,29,30)$, dorsal $(13,19,25,31)$, and ventral $(14,2026)$ views. NS151/10 (1-4); NS151/12 (5-6); NS151/11 (7-8); NS151/7 (9-14); NS151/8 (15-20); NS151/9 (21-26); NS151/33 (2731). Scale bar equal to $5 \mathrm{~cm}$. 
left postzygapophysis, characterized by a sub-elliptical shape with a major axis of about $2.5 \mathrm{~cm}$ and a minor axis of about $1.5 \mathrm{~cm}$, dipping towards the vertebral body at an angle of about $32^{\circ}$. The horizontal distance between the posterior termination of the postzygapophyses and the anterior termination of the right prezygapophysis is about $9 \mathrm{~cm}$. The neural spine shows a basal section with a very flattened elliptical outline (length of about $2.5 \mathrm{~cm}$; width of $0.7 \mathrm{~cm}$ ). Given the size and the shape of its base, the missing neural spine is estimated to be about 5-7 cm high, or about one third of the whole vertebra.

The vertebra NS151/12 (Figure 2.5-6) consists of three pieces found separated at a certain distance on the outcrop surface. The specimen is better preserved on the right side. As for the above described vertebra, we can assume that NS151/ 12 , at the time of exhumation by atmospheric agents, laid with the right side embedded in sediment, exposing the left side to erosion. The specimen has undergone lateral compression that deformed the vertebral articulations of the centrum into flattened ellipses and pushed the postzygapophyses decidedly upwards relative to their original position. The left pedicel and a portion of the postzygapophysis are missing, probably due to breakage (also the front lip and the left half of the centrum are missing). The centrum has a length of about $5 \mathrm{~cm}$ along the dorsal margin, a width of about $3 \mathrm{~cm}$ and a height of $6 \mathrm{~cm}$; due to fractures it is impossible to obtain the exact length along the ventral margin. The posterior lip is a quite stout structure, raised with respect to the body of the centrum, and with a thickness in the median part of about $1 \mathrm{~cm}$; it thickens dorsally and ventrally until reaching a width of about $2 \mathrm{~cm}$. The notochordal canal stops on the posterior side to a depth of about $1.5 \mathrm{~cm}$, whereas it is impossible to observe its termination in the anterior side. The neural arch is fairly compressed, with the right prezygapophysis that has undergone an upwards rotation of about $90^{\circ}$, until it reached the height of the postzygapophyses dorsal tip. The right prezygapophysis is incomplete due to fracture, whereas the postzygapophyses are complete, and show two articular facets, best preserved in their posterior half. These facets have a sub-elliptical shape, with a major axis of about $2.5 \mathrm{~cm}$ and a minor axis of $1.5 \mathrm{~cm}$, and dip toward the center of the vertebral body with an angle of about $33^{\circ}$. The complete absence of the left pedicel makes it impossible to estimate the exact shape of the neural canal. The neural spine, missing due to breakage, shows a sub-rectangular base with beveled edges, and a length of about 2.5 $\mathrm{cm}$ and a width of about $0.8 \mathrm{~cm}$.

The caudal vertebra NS151/11 is composed of three pieces found separately on the outcrop surface. The vertebral body is compressed laterally with a sub-elliptical centrum (Figure 2.7-8). The left side of the centrum is well preserved while the midposterior portion of the right side is missing (also the pedicel and the left prezygapophysis are missing due to breakage). The lip on the anterior side is almost continuous and has an average thickness of $1.5 \mathrm{~cm}$; it re-expands ventrally and dorsally up to reach a width of $2 \mathrm{~cm}$. The lips are stout and bent inwards. The centrum has a length of $4 \mathrm{~cm}$ along the ventral edge and $5 \mathrm{~cm}$ along the dorsal one. The notochordal canal stops at a depth of about 2 $\mathrm{cm}$, both on the anterior and on the posterior sides. The neural arch is laterally flattened with an arrangement of zygapophyses similar to that described above for vertebrae NS 151/10 and NS $151 / 12$. The only visible articular facet, although incomplete, is that of the right postzygapophysis. Overall, the facet has an elliptical shape with a major axis of about $2.5 \mathrm{~cm}$ and a minor axis of about $2 \mathrm{~cm}$, and dip at an angle of about $30^{\circ}$. The base of the neural spine has a sub-rectangular outline, rounded at the posterior edge, while it tapers up to a lanceolate shape in its anterior termination. The base has a length of about $2.5 \mathrm{~cm}$ and a width in the median part of about $0.6 \mathrm{~cm}$.

Specimens NS 151/7, NS 151/8, NS151/9, and NS 151/33 represent broken caudal vertebrae missing their neural arch due to breakage (Figure 2.9-31). The centra are quite laterally compressed, with a shortening of the average width between $30 \%$ (NS 151/7) and $16 \%$ (NS 151/33). NS $151 / 7$ is the largest of the four centra, with a length of 3.7 $\mathrm{cm}$, therefore representing the most anterior one. Considering the rate of decrease in the length of the caudal centra reported by Olson (1962) for Cotylorhynchus hancocki, the distal centrum NS 151/7 was very likely separated from the more anterior one (i.e., NS 151/10) by at least 7-8 caudal vertebrae. The smaller of the centra, hence the more posterior among those recovered, is represented by NS $151 / 33$ with a length of $2.6 \mathrm{~cm}$. Dorsally in all the centra the hemi-cylindrical groove of the neural canal is clearly visible, with an average transverse width ranging from $0.6 \mathrm{~cm}$ in NS151/7 to $0.4 \mathrm{~cm}$ in NS 151/33. The typical groove on the centrum ventral side, previously described for the eight caudal vertebrae of Alierasaurus in articulation (see Romano and Nicosia, 2014), is clearly observable only in NS 151/7 where it assumes an 

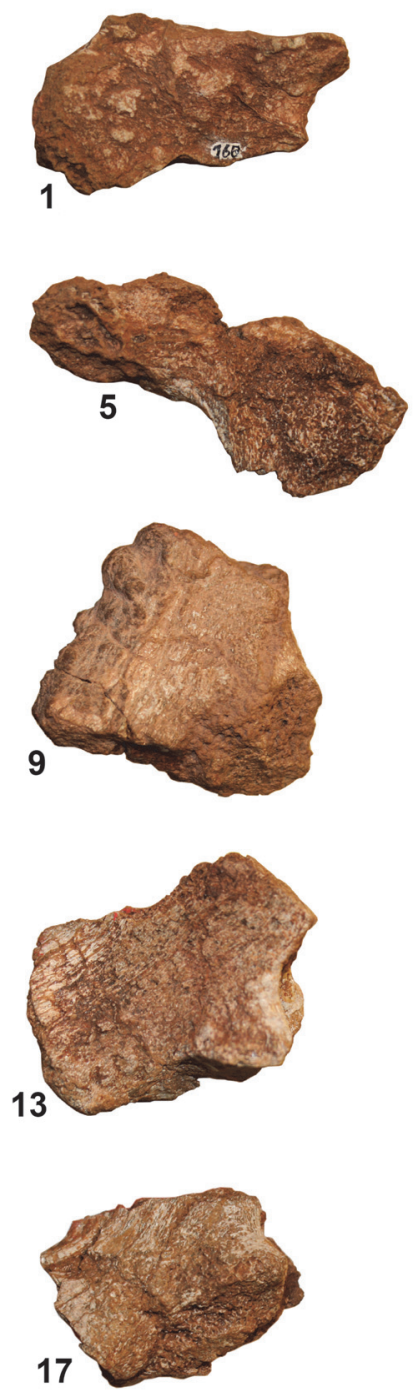
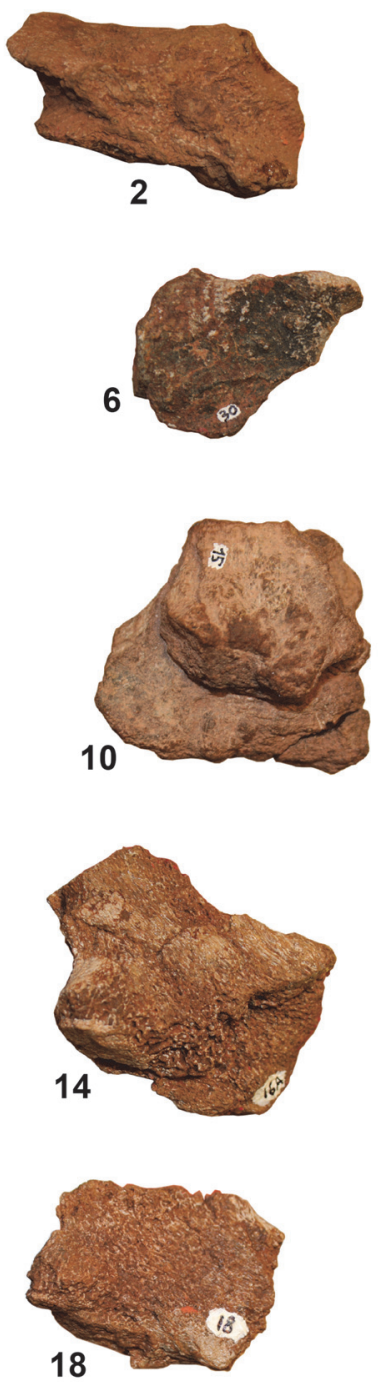
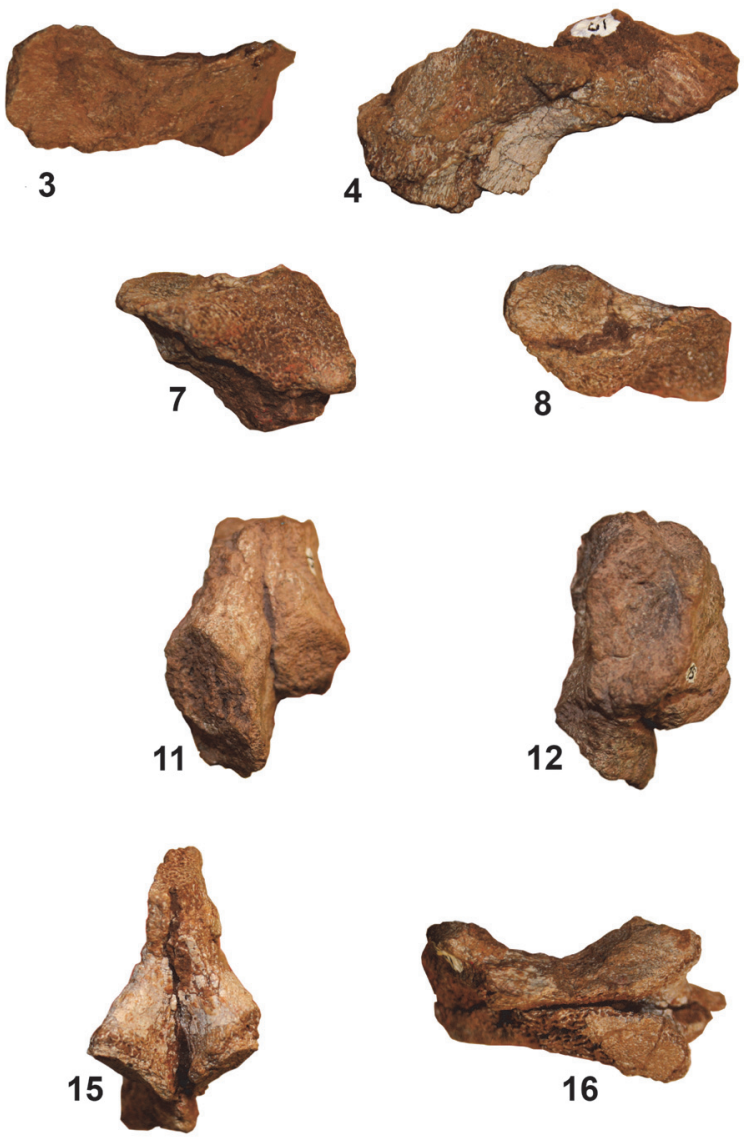

19
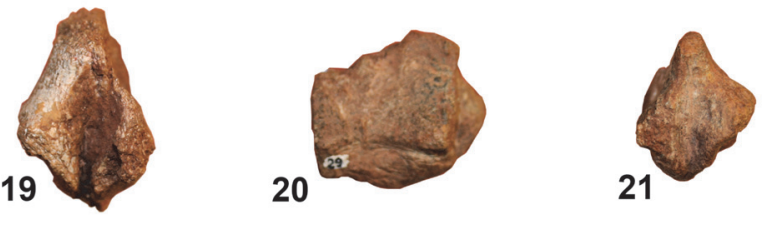

FIGURE 3. New prepared and recovered pre- and postzygapophyses of Alierasaurus ronchii in lateral $(\mathbf{1}, \mathbf{4}, \mathbf{5}, \mathbf{6 , 9}$, $10,13,14,17,18,20)$, medial $(2,7)$, posterior $(11,15,19,21)$, dorsal $(3,8,12)$ and ventral $(16)$ views. NS151/16a-b (1-3); NS151/17 (4-5); NS151/30 (6-8); NS151/15 (9-12); NS151/16 (13-16); NS151/19 (17-19); NS151/29 (20-21). Scale bar equal to $5 \mathrm{~cm}$.

average transverse width of about $0.8 \mathrm{~cm}$. Specimen NS 151/33 shows a structure typical of distal caudal centra, being much longer than high, then taking overall the appearance of an elongated spool (e.g., distal centra in specimen in C. hancocki FMNH UR 578, FMNH UR 703, FMNH UR 883, FMNH UR 884, M.R. pers. obs.).

The above described vertebrae (NS 151/1012), which completely lack transverse processes or co-ossified ribs, can therefore be identified as anterior-middle caudal vertebrae, in any case successive to the disappearance of even the smallest bony protuberance on the centrum (see below).
Among the recovered fragmentary zygapophyses, specimens NS 151/16B, NS 151/17, and NS 151/30 (Figure 3.1-8) represent prezygapophyses with a total size compatible with the more anterior caudal vertebrae recovered (NS 151/10 to12). Specimen NS 151/17 (Figure 3.4-5) is a left prezygapophysis slightly larger than that observed in NS $151 / 10$, then referable to a more anterior caudal vertebra. NS 151/30 and NS 151/16B are right prezygapophyses, the latter showing a very well-preserved articular facet, with a teardrop shape expanded distally and gently tapered proximally (long axis of approximately $3 \mathrm{~cm}$, maximum transverse width equal to $2.1 \mathrm{~cm}$ ). By vertically orienting 

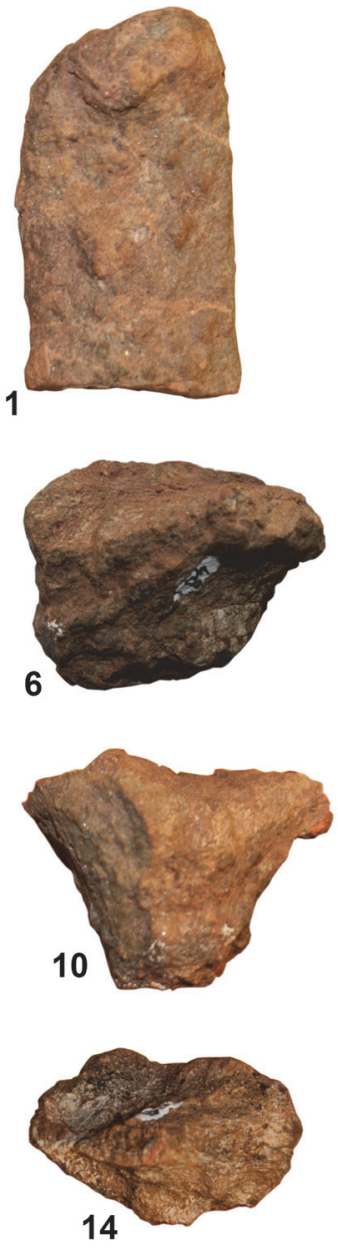
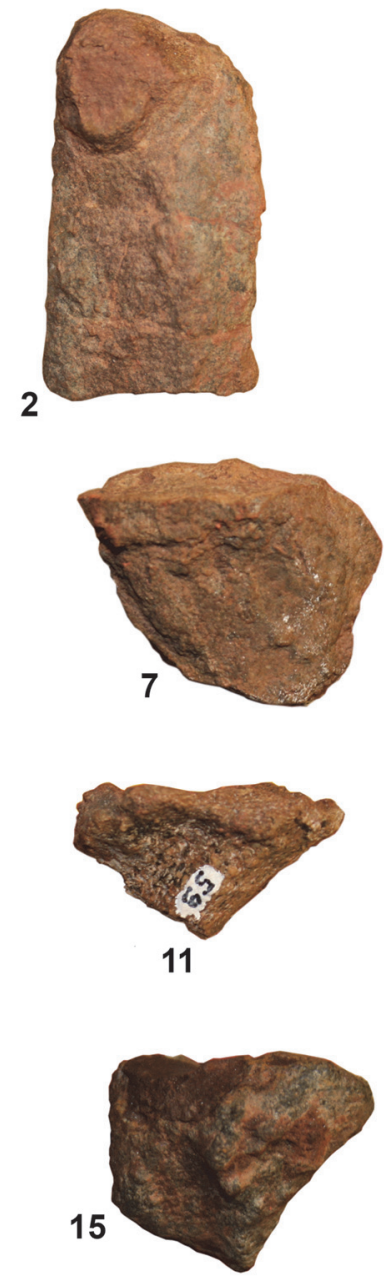
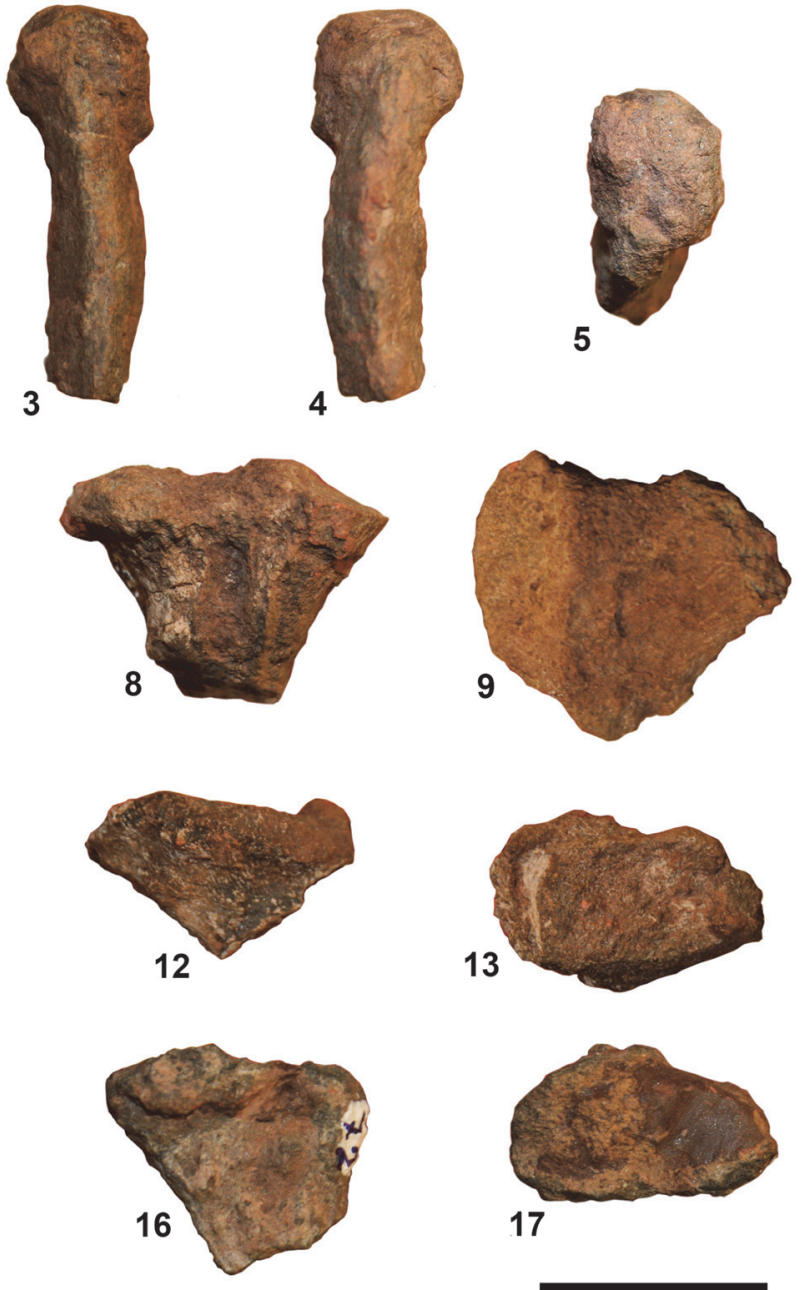

FIGURE 4. Neural spines and proximal portions of haemal arches of Alierasaurus ronchii in lateral (1, 2, 7, 11, 12, 15, 16), dorsal $(5,9, \mathbf{1 3}, 17)$, ventral $(6,14)$, anterior/posterior $(3,4,8,10)$ views. NS151/74 (1-5); NS151/48 (6-10); NS151/59 (11-14); NS151/72 (15-17). Scale bar equal to $5 \mathrm{~cm}$.

the neural arch proximal edge, the prezygapophyses articular surface are decidedly tilted thus confirming the attribution of these specimens to caudal vertebrae (see Reisz, 1986), mostly contiguous to NS 151/10 to 12.

Specimens NS 151/15, NS 151/16A, NS151/ 18 , and NS 151/29 are fragmentary postzygapophyses (Figure 3.9-21) which retain, proximally, the base of the neural spine (thus allowing to observe the spine section). NS 151/16A and NS 151/18 have a size consistent with the more anterior caudal vertebrae NS 151/10-12 and show a long and narrow neural spine section, with a maximum transverse width of about $0.7 \mathrm{~mm}$. NS 151/29 are postzygapophyses significantly smaller than those just described (Figure 3.20-21) and compatible with those characterizing the articulated series (NS
151/19-28, see Romano and Nicosia, 2014, p. 902 , figure 2 ), therefore probably referable to the anterior-middle portion of the tail. Worthy of note are the postzygapophyses NS 151/15 which show a much greater size than that observed in all the recovered and described caudal vertebrae (Figure 3.9-12). The base of the neural spine (the remainder is missing) has a sub-oval section, not transversely flattened as in the typical caudal occupying the middle portion of the tail in large caseids. In particular, the neural spine section is $3.5 \mathrm{~cm}$ long and $2 \mathrm{~cm}$ wide transversely, a considerable size even for an anterior caudal vertebra. As reported above, the close arrangement of the postzygapophyses and the consistent tilt of the articular facets indicate that the specimen NS 151/15 would belong to a caudal vertebra (an anterior one, given 

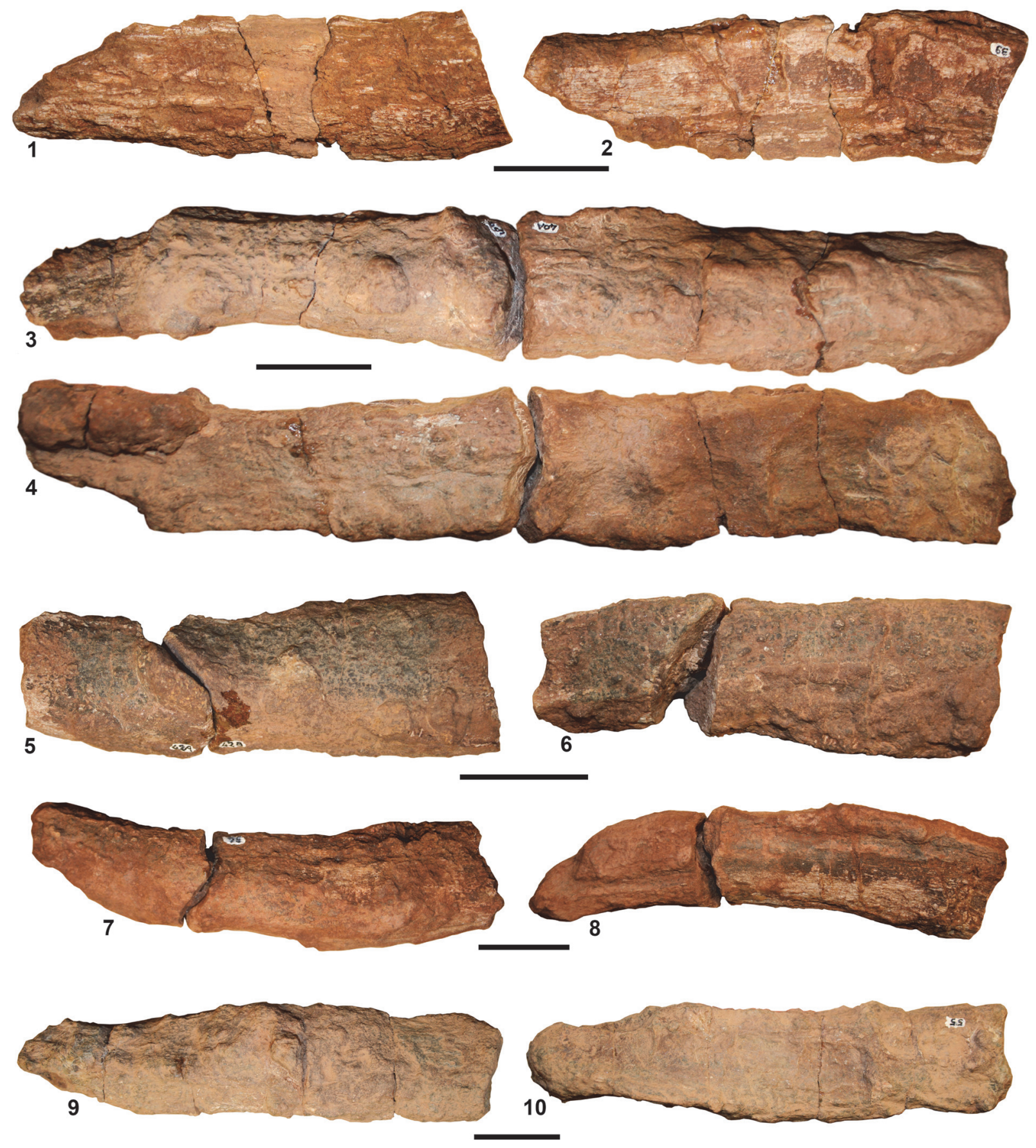

FIGURE 5. Fragmentary recovered ribs of Alierasaurus ronchii in anterior $(\mathbf{1}, \mathbf{3}, \mathbf{5}, \mathbf{7}, \mathbf{9})$ and posterior $(2,4,6,8,10)$ views. NS151/39 (1-2); NS151/40 (3-4); NS151/42 (5-6); NS151/54 (7-8); NS151/55 (9-10). Scale bar equal to $5 \mathrm{~cm}$.

its large size). However, even in the posterior sacrals the postzygapophyses may well be narrower than the prezygapophyses of the same vertebra (according to Reisz et al., 2011 in Ruthenosaurus russellorum the narrowing of the postzygapophyses and the increase of tilting up to about $55^{\circ}$ starts from the first sacral). Thus, taking into account the general great size of postzygapophyses and neural spines section and robustness, an assignment of NS 151/15 to a sacral vertebra cannot be ruled out. The zygapohyseal material described above can be referred to at least seven distinct caudal vertebrae (still interpret- 


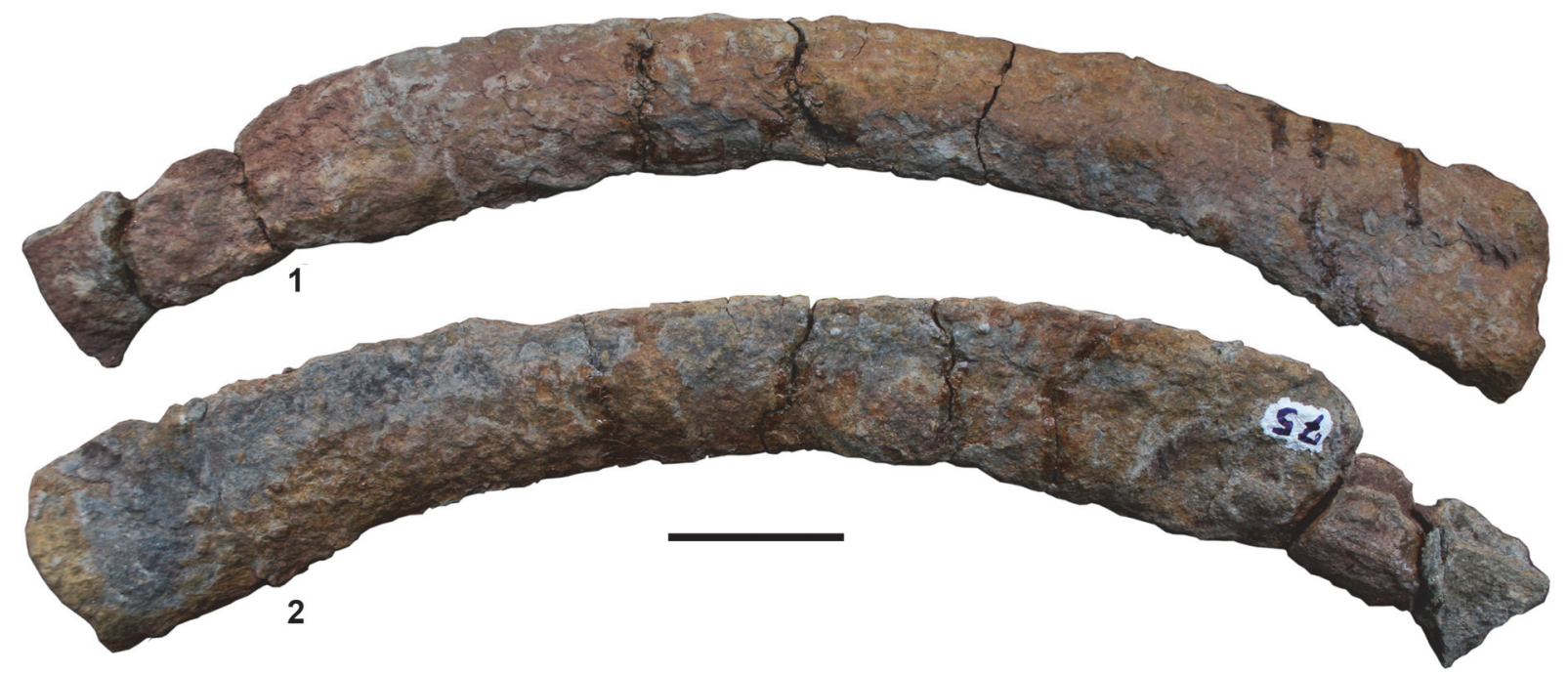

FIGURE 6. Mostly complete dorsal rib NS151/75 of Alierasaurus ronchii. Anterior view (1); posterior view (2). Scale bar equal to $5 \mathrm{~cm}$.

ing the large specimen NS $151 / 15$ as a caudal one).

Among the newly recovered material one of the most diagnostic bone is represented by the neural spine NS 151/74 (Figure 4.1-5), which corroborates the assignment of Alierasaurus ronchii to the Caseidae. The spine central portion (its base is missing due to breakage) has the usual synapsid blade-shape. A very diagnostic feature of the spine results a marked expansion at the distal end, with two bony protrusions, which depart from the spine side and form a sort of plateau, sub-circular in shape, when the neural spine is observed dorsally. According to the characters scored in Benson (2012, data matrix character 166) the transverse enlargement of the neural spine tip to form a 'spines table' represents a unique synapomorphy, in particular of medium to large caseids; however, a slight lateral expansion of the spines can be observed in an incipient way even in the sacrals and 'lumbars' of Casea broilii (FMNH UC 656, holotype; M.R. pers. obs.) and in the dorsals of Casea nicholsi (FMNH UR 86; M.R. pers. obs.) characterized by relatively small body size within Caseidae. Among large caseids, neural spines distally broad to form a plateau, are observable in the cervical, dorsal, lumbar, and sacral vertebrae of Angelosaurus romeri (e.g., FMNH UR 827, FMNH UR 904, FMNH UR 908, FMNH UR 916; M.R. pers. obs.), Cotylorhynchus romeri (e.g., OMNH 655, OMNH 1673, OMNH 4188, FMNH PR 272; M.R. pers. obs.), Cotylorhynchus bransoni (e.g., FMNH UR 915, FMNH UR 925; M.R. pers. obs.) and Cotylorhynchus hancocki (e.g., FMNH UR 622, FMNH UR 703, FMNH UR 706, FMNH UR 710, FMNH UR 720, FMNH UR 821, FMNH UR 893, FMNH UR 894; M.R. pers. obs.). Dorsally expanded neural spines are also recognized in the French caseid Ruthenosaurus russellorum, however, according to Reisz et al. (2011), the top of the spines is not classically anteroposteriorly elongate but shows an autapomorphic diamond-shaped outline. Even if in Benson (2012) the distal plateau is defined as a character only for the dorsal and sacral vertebrae, the relatively small size of the neural spines NS 151/74 is compatible with a proximal caudal vertebra (5 to 8 ) or a cervical one. The latter hypothesis can be reasonably discarded taking into account that in the cervical region at least in Cotylorhynchus romeri the bifid dorsal aspect tends to disappear, and the spine assumes a more rounded section (Stovall et al., 1966). Regarding known caseids, a neural spine distal expansion is observable in the proximal caudal vertebrae at least in Cotylorhynchus romeri (e.g., OMNH 1673, M.R. pers. obs.; see also Stovall et al., 1966, p. 6, figure $2 \mathrm{E}$ ). In the light of the new better preserved spine, the fragmentary specimen NS 151/48, previously recovered, can be interpreted as neural spine distal end (Figure 4.6-10). The specimen has a considerable size, with a length of $3.5 \mathrm{~cm}$ and a transverse width of at least $3.8 \mathrm{~cm}$ (the left side has been broken). Starting from the most proximal preserved portion, which shows a sub-oval section (length $2.5 \mathrm{~cm}$, width $1.7 \mathrm{~cm}$ ), the spine widens consistently on both sides, with two longitudinally 


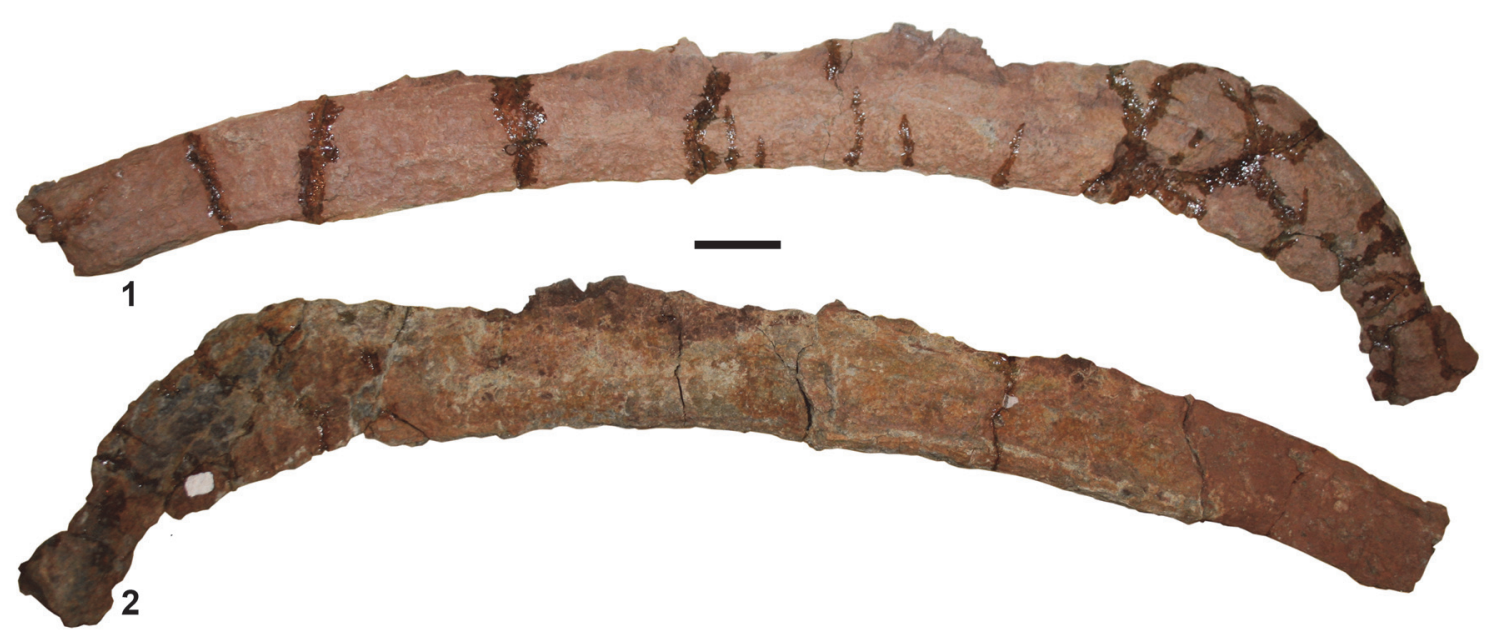

FIGURE 7. Largest dorsal rib found to date for Alierasaurus ronchii (NS151/76). Anterior view (1); posterior view (2). Scale bar equal to $5 \mathrm{~cm}$.

elongated expansions and separated by a groove in dorsal view. Thus, dorsally, the spine assumes a typical bifid aspect very well appreciable in the anterior dorsal of Cotylorynchus romeri (e.g., OMNH 655; M.R. pers. obs.). According to Stovall et al. (1966) the dorsal termination of the spines, expanded laterally and medially indented, is a typical feature of the mid-dorsal vertebrae in C. romeri, as well as the general knobby appearance of the spine. On the posterior side of spine NS 151/48 a longitudinal groove, about $0.4 \mathrm{~cm}$ wide, is observable between two strong bony ridges (Figure 4.8). A very similar groove is present in the dorsal spine FMNH UR 925 referred to Angelosaurus romeri (M.R. pers. obs.). The overall robustness of the spine and the relative size, indicate a possible attribution of the spine to a sacral or a dorsal vertebra.

Specimens NS 151/59 and NS 151/72 represent two anterior portions of haemal arch (Figure 4.11-17). Although the specimens resemble in some way the above described neural spine end, the haemal arch anterior head is fairly asymmetric, with the lateral expansion more developed than the medial one. The approximately flat articular surface for the caudal centra has a sub-oval shape, broader in the proximal half and distally tapered (length equals to $3.3 \mathrm{~cm}$, maximum width in the anterior portion equals to $1.7 \mathrm{~cm}$ ).

Ribs. Specimens NS 151/39, NS 151/40, NS 151/ 42, NS 151/54, and NS 151/55 represent fragmentary ribs that, given their absolute size and the overall robustness, can be referred most likely to the dorsal region (Figure 5). In fact, being larger than the ribs described by Romano and Nicosia
(2014, p. 5, figure 3), the new material can probably be identified as mid-dorsal ribs. All preserved portions show sharp transverse fractures, straight and clean perpendicular to the long axis and parallel to each other, most likely occurred after permineralization (therefore referable to a tectonic phase consistently later than final burial; see Ronchi et al., 2011). On average, the maximum transverse width of the ribs is approximately $3.7 \mathrm{~cm}$ while the maximum length of preserved portion is found in NS 151/40, with a length of $24.5 \mathrm{~cm}$ (Figure 5.3-4). With the exception of the slightly curved NS 151/ 54 , the rib axes are mostly straight, therefore representing the rectilinear portion of the dorsal ribs, comprised between the proximal and the distal curvatures (see Stovall et al., 1966). The rib shows a typical section characterized by a convex anterior side and a flat posterior one. The ribs outer margin is tapered and ends with a sort of bony blade, developed more or less continuously throughout the preserved length. This structure, clearly visible in NS 151/54 and NS 151/40, probably served as the insertion of the $\mathrm{M}$. ilio costalis dorsi (see Romano and Nicosia, 2014). In contrast, the inner border is more rounded, or, as in the case of NS $151 / 55$, consists of two continuous bony ridges separated by a central longitudinal groove. Specimen NS 151/39 is a rib fragment $(11.2 \mathrm{~cm}$ in length, Figure 5.1-2) which, with respect to the just described portions, is overall more flat and with both edges fairly tapered. On the basis of its general structure, the rib may be referred to the last presacrals, being fully compatible with the 'lumbar' region of $C$. romeri (OMNH 1673, M.R. pers. obs.). 

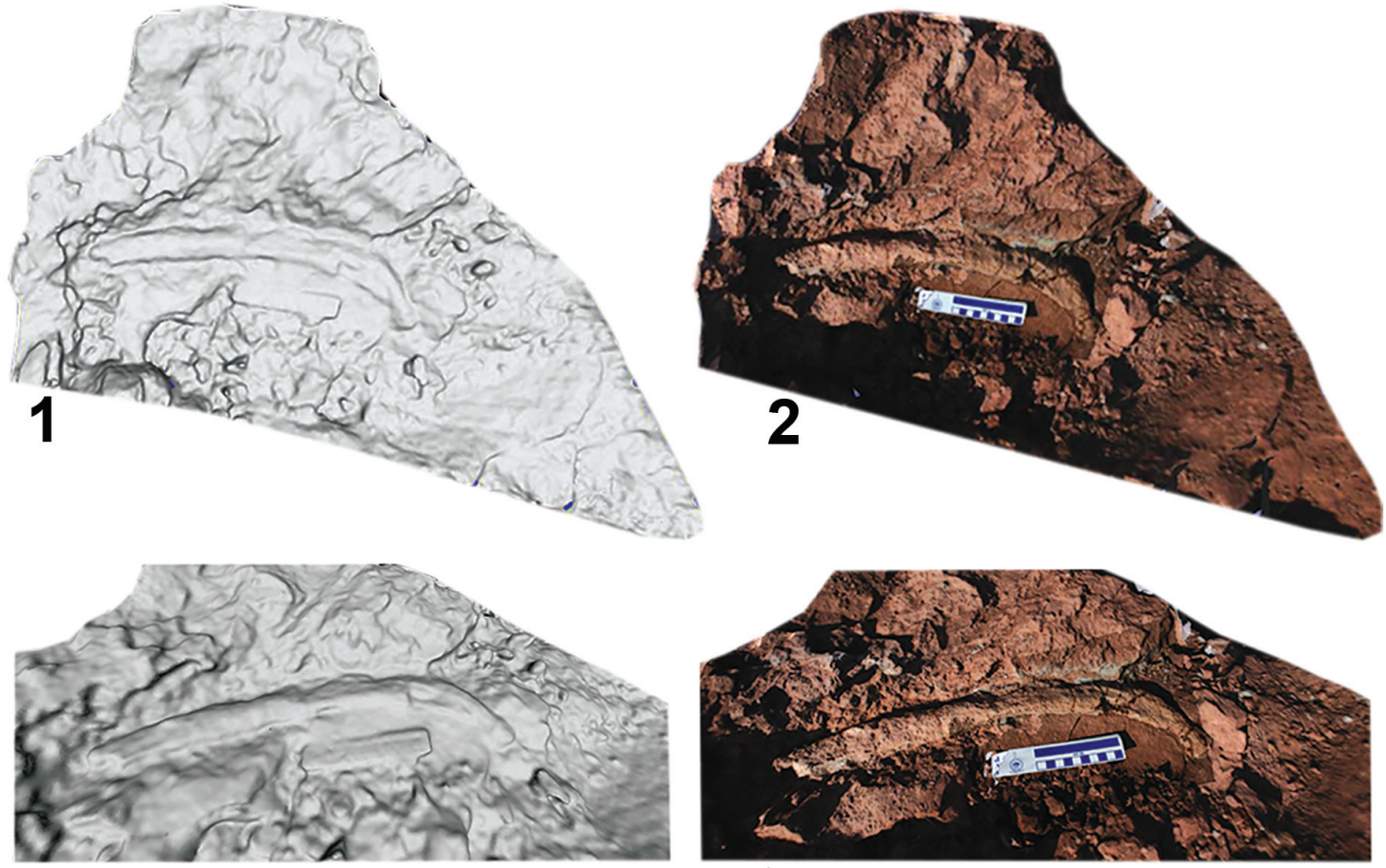

3

4
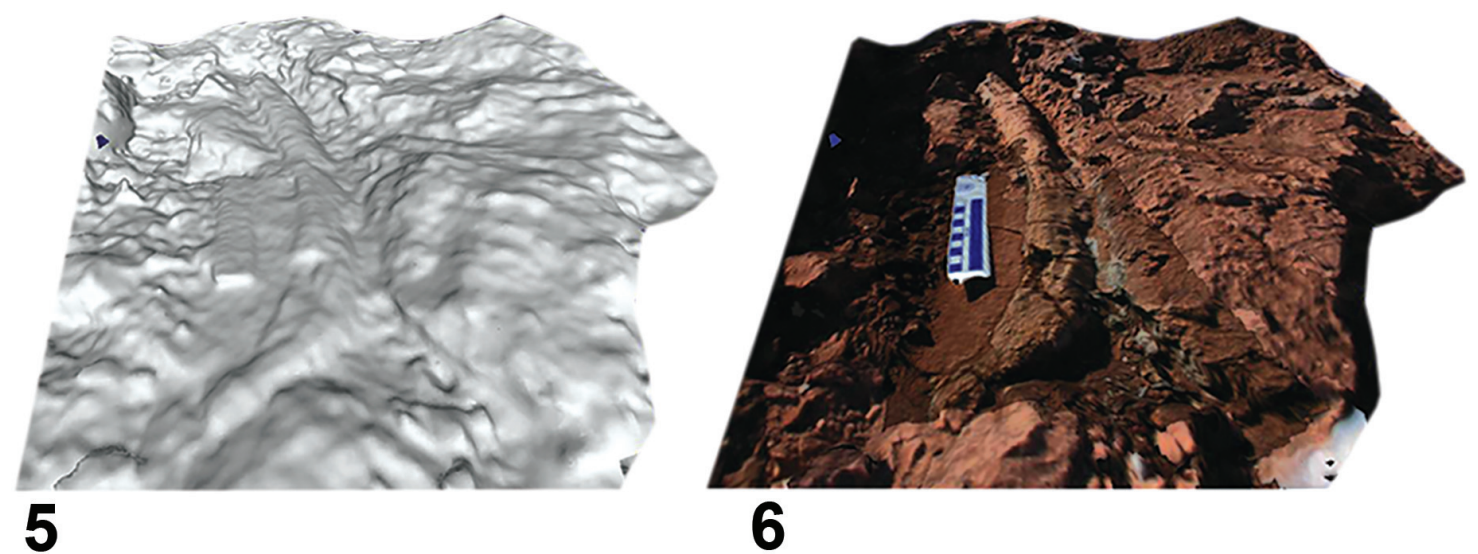

FIGURE 8. Photogrammetric models of the dorsal rib of Alierasaurus ronchii (NS151/76) lying in anterior view in its original position. Meshed models in greyscale $(\mathbf{1}, \mathbf{3}, \mathbf{5})$; Realistic model with textures provided by the original pictures $(2,4,6)$.

Specimen NS 151/75 represents a consistent portion of dorsal rib, with a preserved length measured along the curved axis equal to $27 \mathrm{~cm}$ (Figure $6)$. As for the above described material, the preserved portion shows sharp fractures parallel to each other and perpendicular to the rib long axis. Distally, the rib portion expands, increasing in thickness anteroposteriorly, and shows a weakly concave elliptical surface which probably marks the articulation with the terminal cartilaginous portion of the rib (medio-lateral width equal to $3.7 \mathrm{~cm}$, anteroposterior width equal to $1.5 \mathrm{~cm}$ ). Thus, this structure indicates that the preserved portion represents very likely the distal segment of a dorsal rib. As described above for the dorsal rib portions, the anterior rib surface appears weakly convex while the posterior one is, on the whole, flat. Along both the medial and lateral edge, the rib ends with a beveled hull, thus indicating that the two longitudinal keels, observed in some proximal portions of recovered ribs (e.g., NS 151/69) for the insertion of the M. levator costae (see Romano and Nicosia, 2014), coalesce distally with a single keel; the latter runs until the termination of the rib. 
The new finding NS 151/76 represents by far the largest dorsal rib among those recovered to date, with a preserved portion approximately 52.5 $\mathrm{cm}$ long (Figures 7,8 ). The bone results quite flattened however maintaining a mostly convex anterior and an approximately flat posterior one. Proximally, a system capitulum-tuberculum of considerable size is preserved, with a maximum width of the complex equal to $13.5 \mathrm{~cm}$ (in the largest rib described by Romano and Nicosia, 2014 NS 151/ 62 this distance measures $10.5 \mathrm{~cm}$ ). The capitulum is well preserved, proximally expanded, and tapered distally up to form a kind of collar before re-expanding towards the tuberculum. The concave articular surface has a sub-rhomboid outline, probably due in part to rib post-mortem compression. The long side of the articular area measure $3.1 \mathrm{~cm}$, the short orthogonal one $1.8 \mathrm{~cm}$ in correspondence of the wider central area. The tuberculum is poorly preserved, its proximal portion missing in part due to breakage. However, as typically observed in caseid dorsal ribs, the tuberculum is very close to the axis without forming a welldeveloped process. The rib width immediately distal to the tuberculum (zone of maximum rib width in C. romeri according to Stovall et al., 1966) is 5.3 $\mathrm{cm}$, a very impressive size even for a large caseid.

\section{PHYLOGENETIC ANALYSIS}

The Sardinian caseid was scored with the characters used in Romano and Nicosia (2015) searching for a possible phylogenetic position for the taxon within Caseasauria. Given the highly incomplete nature of the holotype, it was possible to score the taxon only for 10 'qualitative' characters out of a total of 477 characters used in Romano and Nicosia (2015). In addition, five additional morphometric characters were built based on the fourth metatarsal and proximal phalanx of the fourth digit (see Appendix 2). The entire string for Alierasaurus ronchii and scoring for the new characters in the other taxa are given in Appendix 3. The new morphometric characters were scored using the gap-weighting method of Thiele (1993), using the same procedure found in Romano and Nicosia (2015). In particular, the morphometric characters were named using 32 character states designated as follows: $0,1,2,3,4,5,6,7,8,9$, A, B, C, D, E, F, G, H, I, L, M, N, X, P, Q, R, S, T, U, V, $Z$, and $W$. The new data matrix was subjected to a parsimony analysis using the software PAUP* 4.0b10 for Windows (Swofford, 2002). The morphometric characters scored with the gap-weighting method were ordered (see Thiele, 1993;
Romano and Nicosia, 2015), whereas the discrete characters were weighted 32 , in accordance to the number of states used in morphometric characters. This implies that the discrete characters and the ordered morphometric ones have equivalent initial weight for the parsimony analysis. The heuristic search algorithm was selected, with 1000 addition sequence replicates to avoid the searches from becoming trapped in a local tree-length minimum (Maddison, 1991). Both the accelerated (ACCTRAN) and delayed transformations (DELTRAN) were selected leading roughly to the same evolution of the characters scorable in Alierasaurus. Minor differences, which, however, does not affect the interpretation of the characters evolutions, are reported case by case below. Following the same procedure of Romano and Nicosia (2015) to obtain the more satisfying Reference Topology, the taxa Casea halselli and T. texensis were immediately excluded from the analysis. Also the basalmost caseid Eocasea martini is not included in a first analysis for the same reasons reported in Romano and Nicosia (2015).

The first analysis, with 15250876 rearrangements tried, found a single tree with a total length of 31606 steps, consistency index $(\mathrm{Cl})$ of 0.532 , homoplasy index $(\mathrm{HI})$ of 0.468 , and retention index (RI) of 0.469. To facilitate the reading of the new topology, Ruthenosaurus russellorum and Angelosaurus dolani were simply pruned (see Romano and Nicosia, 2015), obtaining the cladogram shown in Figure 9.1. In the new topology, Alierasaurus ronchii appears as the sister taxon of the genus Cotylorhynchus, within the clade ' $Q$ ' consisting of Cotylorhynchus + (Angelosaurus + Ennatosaurus). In Figure 9 the values of bootstrap, jackknife, and Bremer support analyses are reported. As already discussed in Romano and Nicosia (2015), the more derived groups of caseids are very weak in each of the three analyses, with a value of Bremer support equal to 1 for clades $Q, R$, $\mathrm{S}, \mathrm{T}, \mathrm{U}$, and $\mathrm{V}$ (i.e., these groups disappear as soon as a one step longer cladogram is considered). The value for the remaining nodes is identical to that obtained in Romano and Nicosia (2015, p. 9, figure $3 \mathrm{~B}$ ), where the basal portion of caseids and Casesauria is much better supported (Bremer support between 28 and 8 ). It is important to keep in mind that the values in the present work have absolute values about 10 times greater than those calculated in classical phylogenetic analyses, largely due to the high number of ordered character states required by the gap-weighting method (see Druckenmiller and Russell, 2008; Romano 
and Nicosia, 2015). For a discussion on the meaning of the bootstrap and jackknife in analysis using the gap-weighting method, see Romano and Nicosia (2015).

The position of Alierasaurus in the obtained topology is confirmed by the scoring of the following characters and states: 1) phalangeal distal articular surface is oriented ventrodistally (character 475), a synapomorphy unique to Caseasauria (ACCTRAN) or to Caseidae (DELTRAN; in fact the condition is unknown in Eothyris); 2) sacral and dorsal neural spines with a transversely expanded dorsal end, which forms a spine table (character 431), a synapomorphy of caseids more derived than Casea broilii (ACCTRAN; even if the condition is not known in Caseopsis agilis, Caseoides sanangeoloensis, Angelosaurus greeni, Ennatosaurus tecton, and Euromycter rutenus) or more derived than Euromycter (DELTRAN; in fact the condition is unknown in Euromycter); 3) ventral flexor tubercle on ungual phalanges represented by paired eminences, a medial and a lateral one (character 477 ), placed by parsimony as unambiguous synapomorphy of clade ' $Q$ ' (ACCTRAN) or of clade ' $T$ ' (DELTRAN; in fact the condition is not known in Angelosaurus romeri, Angelosaurus greeni and Ennatosaurus tecton); 4) low tuberculum on dorsal ribs characterized by an expanded cup-like articular surface (character 434), a synapomorphy of caseids more derived than C. broilii (ACCTRAN) or more derived than Euromycter (DELTRAN; in fact the condition is not known in Euromycter), however not scorable in 'Casea' nicholsi, Caseoides sanangeloensis, Cotylorhynchus bransoni, Cotylorhynchus hancocki, Angelosaurus romeri, and Angelosaurus greeni, whereas in Ennatosaurus tecton there is a reversion to state 1 (tuberculum reduced to low tuberosity); 5) dorsal neural spines relatively short (approximately 1.5 times centrum height or lower, character 425), a character common to all taxa considered in the analysis, except in Varanops and Ophiacodon (character state 1) and in Dimetrodon, Sphenacodon, and Edaphosaurus with character state 2 (very tall neural spine, character state acquired convergently in the Sphenacodontia and Edaphosaurus); 6) transverse processes on dorsal vertebrae extending far laterally (character 429), a synapomorphy of the group Edaphosaurus + Caseasauria, even if the character is not scorable in Caseopsis agilis, Caseoides sanageloensis, Angelosaurus greeni, Euromycter rutenus, Oromycter dolesorum, and Eothyris (the state is also acquired convergently in the Sphenacodontia); 7) dorsal and sacral neural spines with a transversely compressed cross section (character 432), a character present in all taxa considered in the analysis except for Dimetrodon and Edaphosaurus whose neural spines convergently acquired a circular and rod-like section, character state 1 (thus it represents a symplesiomorphy, which, however, does not preclude the appartenance of Alierasaurus to the Caseidae); 8) dorsal rib shafts strongly arched proximally, identifying a 'barrel-shaped' trunk region (character 433), a synapomorphy characterizing the clade Edaphosaurus + Caseasauria (node ' $G$ '), even if the condition is not known in Caseoides sanangeloensis, Angelosaurus greeni, Euromycter rutenus, Oromycter dolesorum, and Eothyris (the state of the character is convergently present in Diadectes, very likely linked to the barrel-shape body structure in high-fiber herbivorous); 9) calcaneum length conspicuously greater than width (character 468), a synapomorphy of Edaphosaurus + Caseasauria (ACCTRAN) or of caseids more derived than Oromycter (DELTRAN; the condition in fact is not known in Edaphosaurus, Eothyris and Oromycter) although the condition is unknown in 'Casea' nicholsi, Caseoides sanangeloensis, Cotylorhynchus romeri, Angelosaurus romeri, Angelosaurus greeni, Ennatosaurus tecton, (the state is also acquired convergently in Dimetrodon); 10) a low height:width ratio in ungual phalanges (ratio <1.1, character 476), a character shared by all considered taxa except for Dimetrodon and Edaphosaurus which convergently acquired phalanges proportionately more high and narrow (however the condition is not known in Caseopsis agilis, 'Casea' nicholsi, Caseoides sanangeloensis, Angelosaurus romeri, Angelosaurus greeni, Euromycter rutenus, and Eothyris).

The position of Alierasaurus ronchii as the sister taxon of the genus Cotylorhynchus is supported by the morphometric ratios on metatarsal IV and the proximal phalanx of pedal digit fourth (characters 478-480, 482). In particular, the Sardinian caseid is autapomorphic for character 478 (passage 6->U), with a proximal width of MT-IV larger than the distal one. The ratio in $C$. romeri and $C$. bransoni is far lower than 1 (respectively 0.87 and 0.81 ) while in Alierasaurus it reaches 1.24. The second more influential ratio is that between the proximal width of pedal phalanx IV-I and the proximal width of metatarsal MT-IV (character 479, passage $X->7$ in ACCTRAN and L->7 in DELTRAN), with Alierasaurus being autapomorphic in having a proximal phalanx width significantly lower to that of the metatarsal (in the Sardinian caseid, the ratio is 

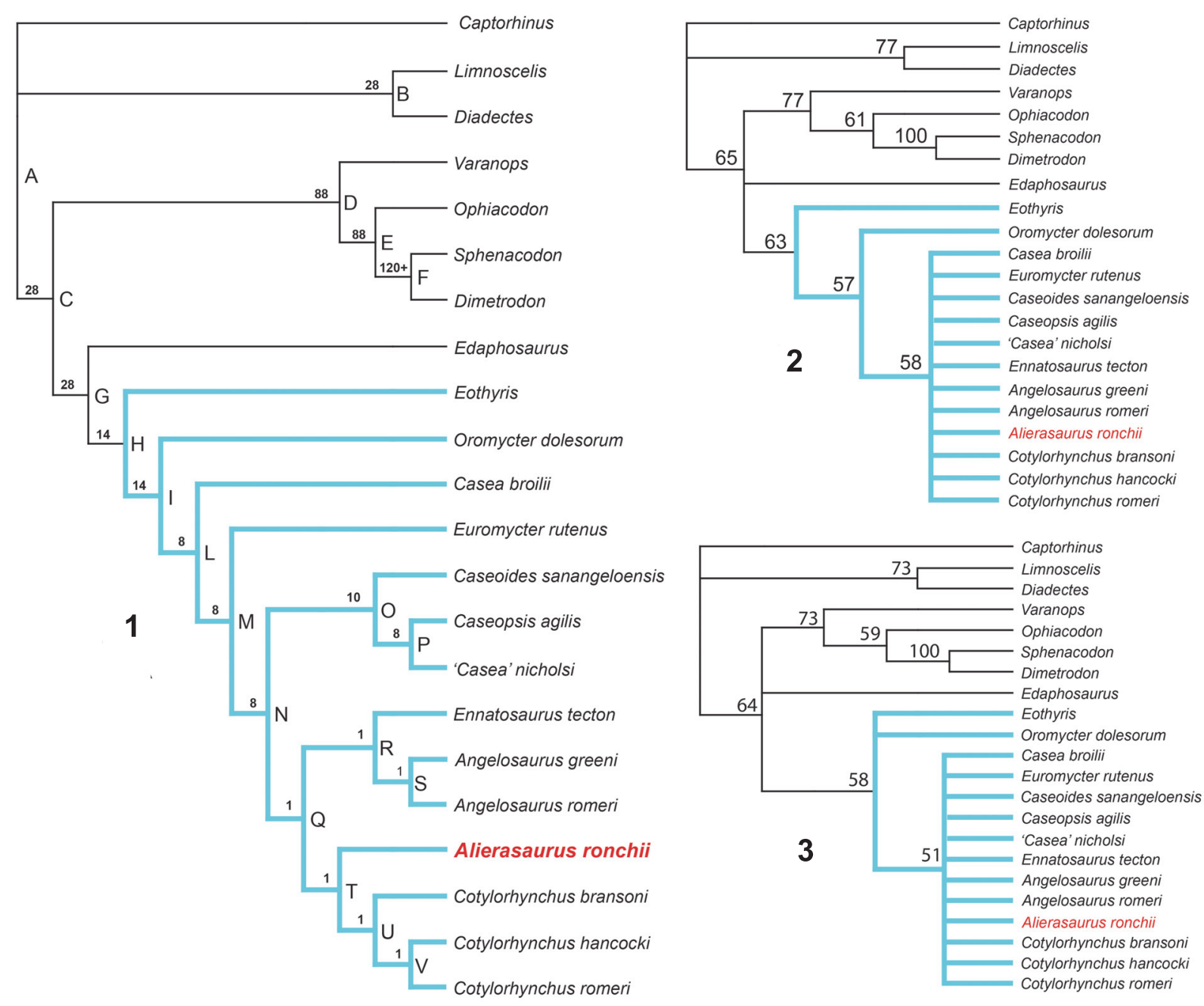

FIGURE 9. Topology obtained including Alierasaurus in a new cladistics analysis of Caseidae. Obtained cladogram showing the Bremer support (1); Result of the bootstrap analysis (2); Result of the jackknife analysis (3). Caseasauria reported in blue.

0.87 , while in C. bransoni and C. romeri it respectively equals to 1.19 and 1.27). The Sardinian caseid is also autapomorphic in having a ratio between the mid-axis narrowing of the fourth metatarsal and its proximal width (character 480 , passage $D->0$ ), with a metapodial overall more slender than respect to the condition observed in $C$. romeri and $C$. bransoni (ratio equals to 0.39 in Alierasaurus; 0.62 and 0.65 respectively in $C$. bransoni and C. romeri).

For completeness, in a second analysis was also included the basal caseid Eocasea martini (Reisz and Fröbisch, 2014). The scoring for the taxon and the specifics of the obtained topology are given in Appendix 4; the obtained topologies are shown in Figure 10. Not including in this analysis other crucial taxa (e.g., Oedaleops, Vaughnictis, Datheosaurus, Callibrachion) major discussion about the basal portion of Casesauria is inappropriate; then Eocasea is considered simply as another polarizing operational taxonomic unit for this second analysis.

The analysis, with 5609072 rearrangements tried, found three equally parsimonious trees with a total length of 32944 steps, with a consistency index $(\mathrm{Cl})$ of 0.532 , a homoplasy index $(\mathrm{HI})$ of 0.468 , and a retention index (RI) of 0.469 . In the strict consensus tree (Figure 10.1), the basal part of Caseasauria is not resolved, with Eocasea and Eothyris forming a basal polytomy. The inclusion of Eocasea leads to some interesting changes in the topology. Angelosaurus greeni represents here the sister group of Limnoscelis, probably for the extreme convergence in the robust appendicular skeleton available and by the lack in $A$. greeni of available cranial material for character scoring (see 

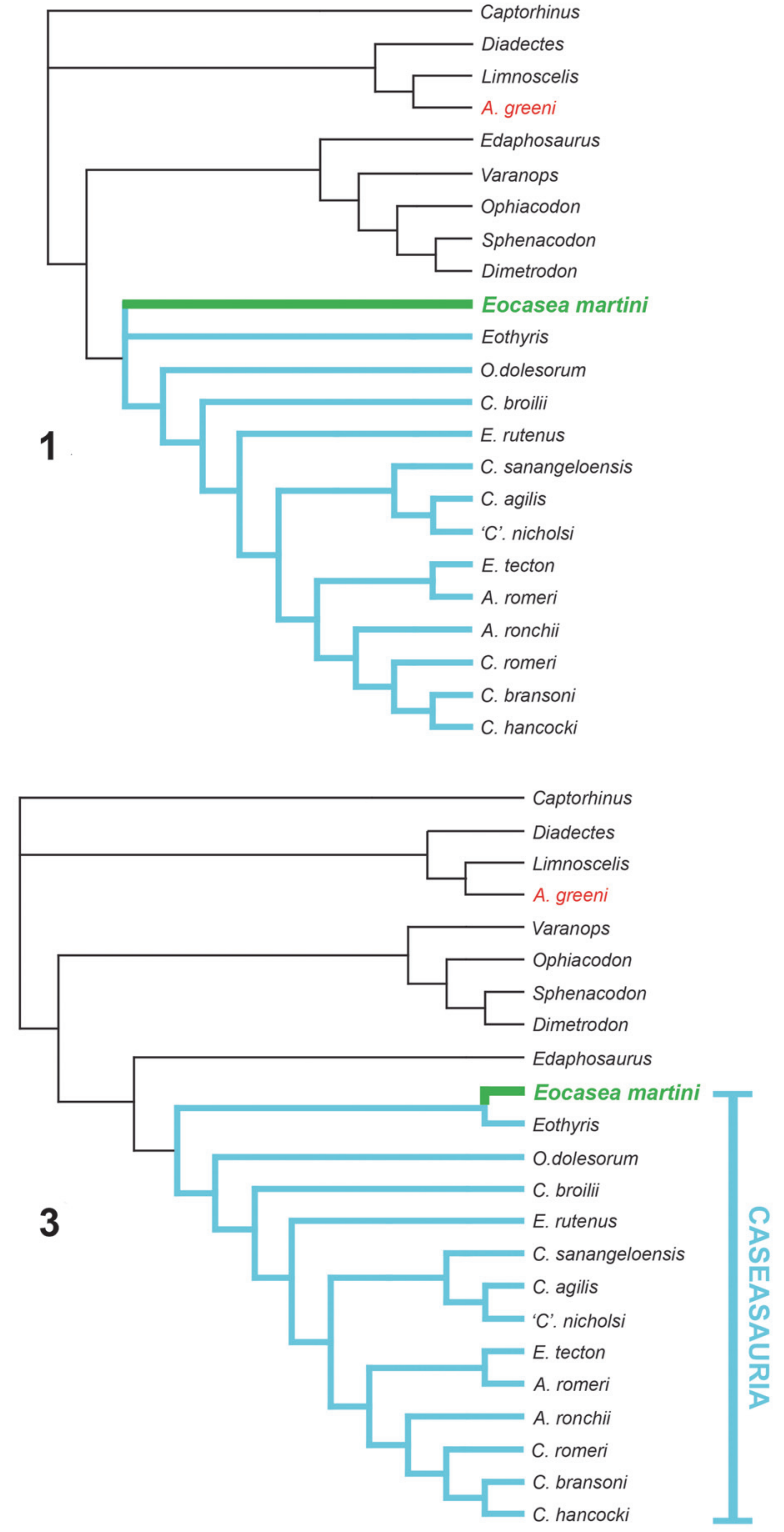
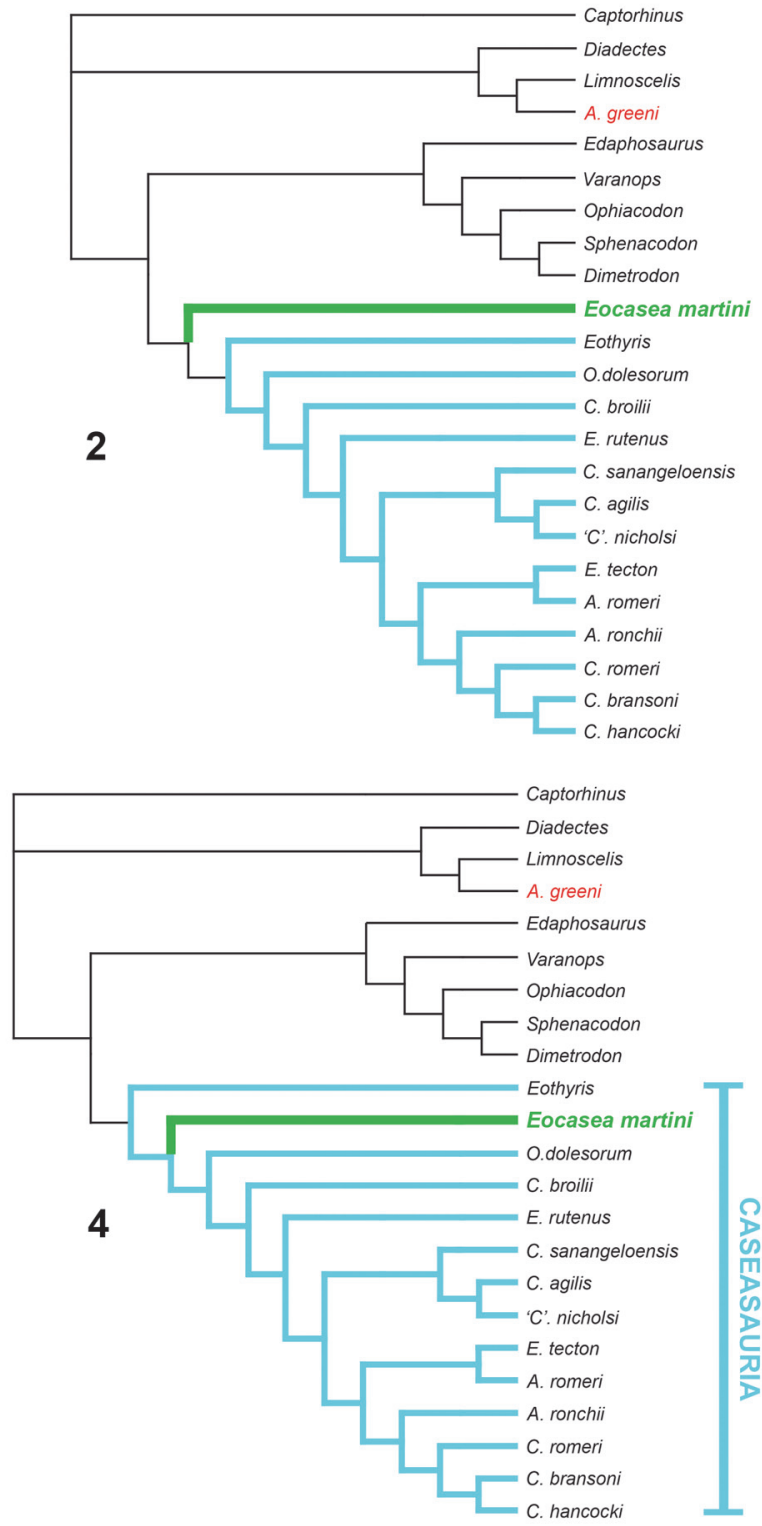

FIGURE 10. Cladograms obtained by including the basal caseid Eocasea martini (in green) in the cladistic analysis. Strict reduced consensus of three equally parsimonious trees with basal Caseasauria (in blue) not resolved (1); $E$. martini falling more basal then Eothyris could be external to Caseidae (2); E. martini as sister taxon of Eothyris, thus representing an eothyridid (3); E. martini represents the most basal caseid as suggested by Reisz and Fröbisch (2014) (4).

also Romano and Nicosia, 2015). As obtained by Benson (2012) we find a sister group relationship between $C$. bransoni and $C$. hancocki, while $C$. romeri is located at the base of the Cotylorhynchus clade. Another interesting result is the new position of Edaphosaurus, found as the sister taxon of the clade Varanops +Ophiacodon +Sphenacodon + Dimetrodon, while Caseasauria assumes once again the traditional basal position among synap- sids. However, these genera of synapsids were used only to test the monophyly of caseids and to search for possible phylogenetic relationships within Caseasauria. Taking into account the limited number of non-Caseasauria genera considered, any indication or inferences on a larger scale in the phylogeny of synapsids is considered inappropriate and beyond the scope of the present work. 


\section{DISCUSSION AND CONCLUSIONS}

The new material recovered and described here presents new information regarding the Sardinian caseid Alierasaurus ronchii from the Permian Cala del Vino Formation. This specimen is important not only because it is the first vertebrate fossil from this rock unit but also because it is the first non-therapsid synapsid from Italy. Given the similarity of preservation, the compatibility in sizes between the various elements, and the total absence of duplicate and repeated bones, all the material can be referred to the holotypic individual of Alierasaurus ronchii. Among the newly described bones, the vertebral and ribs material shows a general structure typical of caseids synapsids. The most diagnostic of the new elements is the caudal neural spine NS 151/74 which, with its bifid and laterally expanded distal end, corroborates the assignment of $A$. ronchii to the Caseidae.

Our phylogenetic analysis including Alierasaurus places the Sardinian taxon among the derived caseids, as the sister group of the genus Cotylorhynchus. The synaphomorphies identified in Alierasaurus are the orientation of the phalangeal distal articular surface, which becomes ventrodistal (synapomorphy of Caseidae), sacral, and dorsal neural spines with a transversely expanded dorsal tip, forming a spine table (synapomorphy of caseids more derived than Euromycter), and a ventral flexor tubercle on ungual phalanges represented by paired eminences, a medial and a lateral one (unambiguous synapomorphy of clade ' $T$ '; Figure 9). In addition, the construction of the fourth metatarsal of Alierasaurus is autapomorphic as already highlighted in the original diagnosis by Romano and Nicosia (2014). In particular, the metatarsal is, on the whole, slenderer (more marked narrowing at the mid-axis) and characterized by a very developed proximal width, greater than the distal one (in C. bransoni and C. hancocki, the condition is exactly the opposite). Despite the result of a single cladogram, we emphasize that it was possible to score the taxon from only a few characters (only 15 out 482). Therefore, it cannot be ruled out that there might be a change in the topology with the recognition and encoding of further and more diagnostic material (both cranial and post-cranial), and due to the inclusion of additional taxa.

As already described in Romano and Nicosia (2014) the new material confirms an orientation of the dorsal ribs with the proximal portion facing outward and upward, then identifying a very large barrel-shaped trunk. This conformation allows us to infer a limited vertical movement and consistent anteroposterior one of dorsal ribs during ventilation (see also Reisz et al., 2011). The Sardinian taxon, and probably all caseids, were characterized by a primitive costal aspiration pump, a breathing mechanism where lung ventilation is fully guaranteed by ribs rotation ('costal aspiration' sensu Brainerd, 1999). Manipulation of the Sardinian material indicates that, during ventilation, the dorsal ribs should rotate using as hinges the capitulum oval facet and the elongated elliptical tuberculum, resulting in a diagonal movement with major anteroposterior component. In extant reptiles, the primitive costal aspiration pump, with a front and back swing of the ribs during ventilation, is well exemplified by the squamate Iguana iguana Linnaeus, 1758. In this species, a posterior rotation of the ribs, produced by the action of the $M$. transversalis and $M$. retrahenentes costarum, increases thoracic pressure, while anterior rotation, generated by both internal and external intercostales muscles decreases pressure (Carrier, 1989). Similar lung ventilation represented, most likely, the breathing mechanism in the stem amniotes barrel-shaped caseids.

The sturdiness and shape of dorsal ribs, and the huge vertebrae-ribs system reconstructed on the basis of the specimen NS 151/76, indicate a very large barrel-shaped body typical of an herbivorous tetrapod (Hotton et al., 1997; Sues and Reisz, 1998). Caseids were among the first land vertebrates to occupy the role of primary consumers (Olson, 1962) and the enormous size reached by the taxon, Alierasaurus ronchii is most likely related to this specialized herbivorous lifestyle. Herbivorous tetrapods, in fact, are generally characterized by a wide trunk region with bulk and long digestive tracts, essential for fiber fermentation (Sues and Reisz, 1998). The increase in size and weight is consistent with trend observed within caseid evolutionary history (Olson, 1962; Olson and Barghusen, 1962; Olson, 1968; Reisz, 1986; Reisz, 2005). Regardless of whether the 'Cope's Rule' is accepted in its canonical sense or "viewed as describing evolution from small size rather than toward large size" (Stanley, 1973, p. 22), the increase in body size within a lineage is a phenomenon that appeared several times in the history of life, leading, evidently, advantages in terms of adaptation and fitness. Large body size decreases the possibility of attack by predators (Pianka, 1995), improves metabolic efficiency (Gould, 1966), extends the longevity of an individual maximizing the period of reproductive activity (Hotton et al., 1997), reduce the annual mortality (Stanley, 1973), and can make animals more independent 


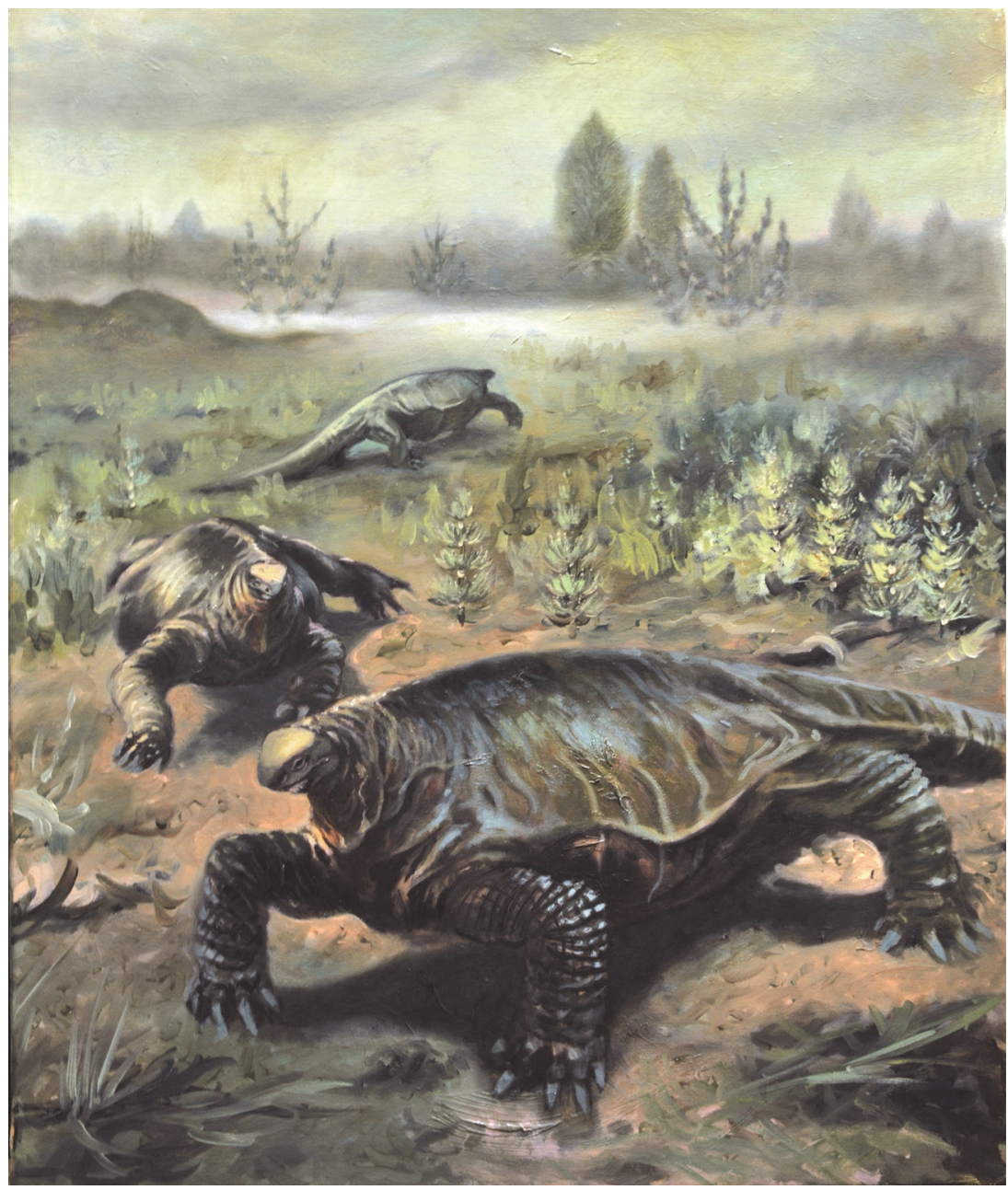

FIGURE 11. In vivo reconstruction of Alierasaurus ronchii by the Italian artist Emiliano Troco (oil on canvas). The reconstruction has been obtained taking as reference for comparison the mounted skeletons of Cotylorhynchus romeri OMNH 655, OMNH 1673 and the cast on slab MSNM V7161.

from the external environment through an increase in heat retention (Newell, 1949). As stated by Newell (1949, p. 120) "the large animal can more efficiently maintain the required equilibrium of the life processes than the small one." In addition, in primary consumers, large size and bulky torsos promote the cellulysis of the high-fiber plants tissue (Hotton et al., 1997). For all the above, in caseids evolution, natural selection has favored the evolution of large forms, with Alierasaurus ronchii (Figure 11), being one of its largest representatives.

\section{ACKNOWLEDGEMENTS}

M. Jansen is warmly thanked for the support in Ct-scan and for Cone beam specimen reconstruction. A. Fiorillo is thanked for all the useful corrections and suggestions that greatly improved the manuscript. The authors gratefully acknowledge the A.P.P.I. for providing and having supplied direct assistance to field work. A. Carpana, A. Pirondini, A. Giamborino, C. Nicoli, D. Bonadonna, E. Sacchi, F. Battista, P. Citton, and T. Coppola are warmly thanked for their crucial help in the field. We also thank the "Soprintendenza Archeologia, Belle Arti e Paesaggio per le province di Sassari, OlbiaTempio e Nuoro" for its assistance and for the authorization to study the material.

Part of this work was made possible by financial support to M.R. from the Alexander von Humboldt-Foundation (Sofja Kovalevskaja-Award to Jörg Fröbisch "Early Evolution and Diversification of Synapsida" of the German Federal Ministry of Education and Research). 


\section{REFERENCES}

Baucon, A., Ronchi, A., Felletti, F., and Neto de Carvalho, C. 2014. Evolution of crustaceans at the edge of the end-Permian crisis: ichnonetwork analysis of the fluvial succession of Nurra (Permian-Triassic, Sardinia, Italy). Palaeogeography, Palaeoclimatology, Palaeoecology, 410:74-103.

Benson, R.B.J. 2012. Interrelationships of basal synapsids: cranial and postcranial morphological partitions suggest different topologies. Journal of Systematic Palaeontology, 10:601-624.

Berman, D.S. and Henrici, A. C. 2003. Homology of the Astragalus and structure and function of the tarsus of Diadectidae. Journal of Paleontology, 77:172-188.

Brainerd, E.L. 1999. New perspectives on the evolution of lung ventilation mechanisms in vertebrates. Experimental Biology Online, 4:11-28.

Brocklehurst, N., Romano, M., and Fröbisch, J. 2016. Principal component analysis as an alternative treatment for morphometric characters: phylogeny of caseids as a case study. Palaeontology, 59:877886.

Carrier, D.R. 1989. Ventilatory action of the hypaxial muscles of the lizard Iguana iguana: a function of slow muscle. Journal of Experimental Biology, 143:435-457.

Cassinis, G. and Ronchi, A. 2002. The (late-) post-Variscan continental succession of Sardinia. Rendiconti Società Paleontologica Italiana, 1:77-92.

Cassinis, G., Cortesogno, G., Gaggero, L., Pittau, P., Ronchi, A., and Sarria, E. 2000. Late Palaeozoic continental basins of Sardinia. Field trip guidebook, 15-18 September, 1999. International Field Conference on "The Continental Permian of the Southern Alps and Sardinia (Italy). Regional reports and general correlations," 15-25 Sept. 1999, Brescia.

Cassinis, G., Durand, M., and Ronchi, A. 2003. PermianTriassic continental sequences of Northwest Sardinia and South Provence: Stratigraphic correlations and palaeogeographical implications. Bollettino Società Geologica Italiana, 2:119-129.

Cassinis, G., Perotti, C., and Ronchi A. 2012. Permian continental basins in the Southern Alps (Italy) and peri-Mediterranean correlations. International Journal of Earth Sciences, 101:129-15.

Cipriani, A., Citton, P., Romano, M., and Fabbi, S. 2016. Testing two open-source photogrammetry software as a tool to digitally preserve and objectively communicate significant geological data: the Agolla case study (Umbria-Marche Apennines). Italian Journal of Geosciences, 135:199-209.

Dilkes, D.W. and Reisz, R.R. 1996. First record of a basal synapsid ('mammal-like reptile') in Gondwana. Proceedings of the Royal Society of London Series B-Biological Sciences, 263:1165-1170.

Dodick, J.T. and Modesto, S.P. 1995. The cranial anatomy of the captorhinid reptile Labidosaurikos mea- chami from the Lower Permian of Oklahoma. Palaeontology, 38:687-711.

Druckenmiller, P.S. and Russell, A.P. 2008. A phylogeny of Plesiosauria (Sauropterygia) and its bearing on the systematic status of Leptocleidus Andrews, 1922. Zootaxa, 1863:1-120.

Gand, G. and Durand M. 2006. Tetrapod footprint ichnoassociations from French Permian basins. Comparisons with other Euramerican ichnofaunas, p. 157177. In Lucas S.G., Cassinis, G., and Schneider, J. W. (eds.), Non-Marine Permian Biostratigraphy and Biochronology. Geological Society of London Special Publications vol. 265, London.

Gould, S.J. 1966. Allometry and size in ontogeny and phylogeny. Biological Reviews, 41:587-640.

Henrici, A.C., Berman, D.S., Lucas, S.G., Heckert, A.B., Rinehart, L.F., and Zeigler, K. 2005. The carpus and tarsus of the Early Permian synaspid Sphenacodon ferox (Eupelycosauria: Sphenacodontidae), p. 106110. In Lucas, S.G. and Zeigler, K.E. (eds.), The Nonmarine Permian. New Mexico Museum of Natural History and Science Bulletin 30. New Mexico Museum of Natural History and Science, Albuquerque.

Holmes, R.B. 2003. The hind limb of Captorhinus aguti and the step cycle of basal amniotes. Canadian Journal of Earth Sciences, 40:515-526.

Hotton. N. III, Olson, E.C., and Beerbower, R. 1997. Amniote origins and the discovery of herbivory, $p$. 207-264. In Sumida, S.S. and Martin, K.L.M. (eds.), Amniote origins, completing the transition to land. Academic Press, San Diego.

Kissel, R.A. and Lehman, T.M. 2002. Upper Pennsylvanian tetrapods from the Ada Formation of Seminole County, Oklahoma. Journal of Paleontology, 76:529545.

Lambertz, M., Shelton, C.D., Spindler, F., and Perry, S.F. 2016. A caseian point for the evolution of a diaphragm homologue among the earliest synapsids. Annals of the New York Academy of Sciences, 1385:3-20.

LeBlanc, A.R.H. and Reisz, R.R. 2014. New postcranial material of the early caseid Casea broilii Williston, 1910 (Synapsida: Caseidae) with a review of the evolution of the sacrum in Paleozoic non-mammalian synapsids. PLoS ONE, 9(12):e115734.

Linnaeus, C. 1758. Systema naturae per regna tria naturae, secumdum classes, ordines, genera, species, cum characteribus, differentiis, synonymis, locis. Laurentii Solvii, Stockholm.

Lopez, M., Gand, G. Garric, J., Körner, F., and Schneider, J. 2008. The playa environments of the Lodève Permian basin (Languedoc-France). Journal of Iberian Geology, Universidad Complutense de Madrid, 34(1):29-56.

Maddin, H.C., Sidor, C.A., and Reisz, R.R. 2008. Cranial anatomy of Ennatosaurus tecton (Synapsida: Caseidae) from the Middle Permian of Russia and the evo- 
lutionary relationships of Caseidae. Journal of Vertebrate Paleontology, 28:160-180.

Maddison, D.R. 1991. The discovery and importance of multiple islands of most-parsimonious trees. Systematic Zoology, 40:315-328.

Michel, L.A., Tabor, N.J., Montañez, I.P., Schmitz, M., and Davydov, V.I. 2015. Chronostratigraphy and paleoclimatology of the Lodève Basin, France: evidence for a pan-tropical aridification event across the Carboniferous - Permian boundary. Palaeogeography, Palaeoclimatology, Palaeoecology, 430:118131.

Modesto, S.P. and Reisz, R.R. 1992. Restudy of PermoCarboniferous synapsid Edaphosaurus novomexicanus Williston and Case, the oldest known herbivorous amniote. Canadian Journal of Earth Sciences, 29:2653-2662.

Modesto, S.P., Lamb, A.J., and Reisz, R.R. 2014. The captorhinid reptile Captorhinikos valensis from the lower Permian Vale Formation of Texas, and the evolution of herbivory in eureptiles. Journal of Vertebrate Paleontology, 34:291-302.

Newell, N.D. 1949. Phyletic size increase, an important trend illustrated by fossil invertebrates. Evolution, 3:103-124.

Olson, E.C. 1962. Late Permian terrestrial vertebrates, U.S.A. and U.S.S.R. American Philosophical Society Transactions, 52:1-224.

Olson, E.C. 1968. The family Caseidae. Fieldiana, Geology, 17:225-349.

Olson, E.C. and Barghusen, H. 1962. Permian vertebrates from Oklahoma and Texas. Oklahoma Geological Survey, 59:5-48.

Osborn, H. F. 1903. On the primary division of the Reptilia into two sub-classes, Synapsida and Diapsida. Science, 17:275-276.

Pianka, E.R. 1995. Evolution of body size: varanid lizards as a model system. American Naturalist, 146:398-414.

Reisz, R.R. 1986. Pelycosauria. Handbook of Paleoherpetology, Part 17A. Gustav Fischer Verlag, Stuttgart.

Reisz, R.R. 2005. Oromycter, a new caseid from the Lower Permian of Oklahoma. Journal of Vertebrate Paleontology, 25:905-910.

Reisz, R.R. and Fröbisch, J. 2014. The oldest caseid synapsid from the Late Pennsylvanian of Kansas, and the evolution of herbivory in terrestrial vertebrates. PLoS ONE, 9(4):e94518.

Reisz, R.R. and Laurin, M. 2001. The reptile Macroleter: First vertebrate evidence for correlation of Upper Permian continental strata of North America and Russia. Geological Society of America Bulletin, 113:1229-1233.

Reisz, R.R. and Sues, H.D. 2000. Herbivory in late Paleozoic and Triassic terrestrial vertebrates, p. 941. In Sues, H-D (ed.), Evolution of Herbivory in Terrestrial Vertebrates. Cambridge University Press, New York.
Reisz, R.R., Godfrey, S.J., and Scott, D. 2009. Eothyris and Oedaleops: do these early Permian synapsids from Texas and New Mexico form a clade? Journal of Vertebrate Paleontology, 29:39-47.

Reisz, R.R., Maddin, H.C., Fröbisch, J., and Falconnet, J. 2011. A new large caseid (Synapsida, Caseasauria) from the Permian of Rodez (France), including a reappraisal of 'Casea' rutena Sigogneau-Russell and Russell, 1974. Geodiversitas, 33:227-246.

Romano, M. 2017a. Long bone scaling of caseid synapsids: a combined morphometric and cladistic approach. Lethaia, doi:10.1111/let.12207.

Romano, M. 2017b. Gut microbiota as a trigger of accelerated directional adaptive evolution: acquisition of herbivory in the context of extracellular vesicles, microRNAs and inter-kingdom crosstalk. Frontiers in Microbiology, 8:721.

Romano, M., Citton, P., and Nicosia, U. 2016. Corroborating trackmaker identification through footprint functional analysis: the case study of Ichniotherium and Dimetropus. Lethaia, 49:102-116.

Romano, M. and Nicosia, U. 2014. Alierasaurus ronchii gen. et sp. nov., a caseid from the Permian of Sardinia, Italy. Journal of Vertebrate Paleontology, 34:900-913.

Romano, M. and Nicosia, U. 2015. Cladistic analysis of Caseidae (Caseasauria, Synapsida): using gapweighting method to include taxa based on poorly known specimens. Palaeontology, 58:1109-1130.

Ronchi, A., Sacchi, E., Romano, M., and Nicosia, U. 2011. A huge caseid pelycosaur from north-western Sardinia and its bearing on European Permian stratigraphy and palaeobiogeography. Acta Palaeontologica Polonica, 56:723-738.

Ronchi, A., Sarria, E., and Broutin, J. 2008. The "Autuniano Sardo": basic features for a correlation through the Western Mediterranean and Paleoeurope. Bollettino Società Geologica Italiana, 127:655-681.

Sacchi, E., Cifelli, R., Citton, P., Nicosia, U., and Romano, M. 2014. Dimetropus osageorum n. isp. from the Early Permian of Oklahoma (USA): a trace and its trackmaker. Ichnos, 21:175-192.

Schneider, J.W., Koerner, F., Roscher, M., and Kroner, U. 2006. Permian climate development in the northern peri-Tethys area - The Lodeve basin, French Massif Central, compared in a European and global context. Palaeogeography, Palaeoclimatology, Palaeoecology, 240:161-183.

Sigogneau-Russell D. and Russell, D.E. 1974. Étude du premier caséidé (Reptilia, Pelycosauria) d'Europe occidentale. Bulletin du Muséum National d'Histoire Naturelle, Série 3, 230:145-215.

Spindler, F., Falconnet, J., and Fröbisch, J. 2016. Callibrachion and Datheosaurus, two historical and previously mistaken basal caseasaurian synapsids from Europe. Acta Palaeontologica Polonica, 61:597-616.

Stanley, S.M. 1973. An explanation for Cope's Rule. Evolution, 27:1-26. 
Stovall, J.W., Price, L.I., and Romer, A.S. 1966. The postcranial skeleton of the giant Permian pelycosaur Cotylorhynchus romeri. Bulletin of the Museum of Comparative Zoology, 135:1-30.

Sues, H.D. and Reisz, R.R. 1998. Origins and early evolution of herbivory in tetrapods. Trends In Ecology \& Evolution, 13:141-145.

Swofford, D.L. 2002. PAUP*: Phylogenetic analysis using parsimony ( ${ }^{*}$ and other methods). Version 4.0b10. Sinauer Associates. Sunderland, Massachussetts.

Thiele, K. 1993. The holy grail of the perfect character: the cladistics treatment of morphometric data. Cladistics, 9:275-304.

Williston, S.W. 1911. Permian reptiles. Science, 33:631632.

Williston, S.W. 1912. Primitive reptiles. A review. Journal of Morphology, 23:637-666. 


\section{APPENDIX 1.}

\section{Composition of bony tubercles}

After a careful analysis all the tubercles result made of bone and are not constituted by metallic incrustations. As first element, it is possible to check the histological section of a rib of Alierasaurus, presented and described by Lambertz et al. (2016, figure 5, p. 11); in the section also the raised portions, forming the typical tubercles, are entirely made of bony cortex.

To be sure, a phalanx and a rib rich in surface tubercles have been scanned at micro CT-scan. The specimens were scanned at the Museum für Naturkunde Berlin using x-ray computed tomography (phoenix|x-ray nanotom s) at $110 \mathrm{kV}, 190 \mu \mathrm{A}$ for $1400 / 360^{\circ}$ projections / segment of the multiscan, and an exposition timing of $750 \mathrm{~ms} /$ projection. The specimen was scanned at a magnification ratio of $x 1.54100859$, and an effective voxel size of $0.03244628 \mathrm{~mm}$ as well as an additional calibration value of 1.313 .

The smaller rib fragment was scanned using x-ray computed tomography at $120 \mathrm{kV}, 200 \mu \mathrm{A}$ for $1400 / 360^{\circ}$ projections / segment of the multiscan, and an exposition timing of $750 \mathrm{~ms} / \mathrm{projec}-$ tion. The specimen was scanned at the same settings for magnification and effective voxel size, with an additional calibration value of 0.795 . No filter was used. Cone beam reconstruction for all specimenswas performed using datos|x-reconstruction software (GE Sensing \& Inspection Technologies $\mathrm{GmbH}$ phoenix|x-ray) The volume was reconstructed out of 1400 saved 16bit - tagged image files (TIF) for each scan.

With this method, metal crusts are clearly identifiable, being represented by a shiny silver patina. As shown in Appendix 1.1 some tubercles (in the bottom right of the phalanx) have a thin metal coating that superficially covers the raised structure. However, the tubercle is composed entirely of bone, without any contrast or composition change compared with the rest of the phalanx (and of the rib). In addition, in Appendix 1.2 is shown how the bones are characterized by transverse fractures, where a metallic coating is precipitated during diagenesis. Even at the macroscopic level, in two broken tubercles of the same phalanx the cortex bony tissue is very well visible.

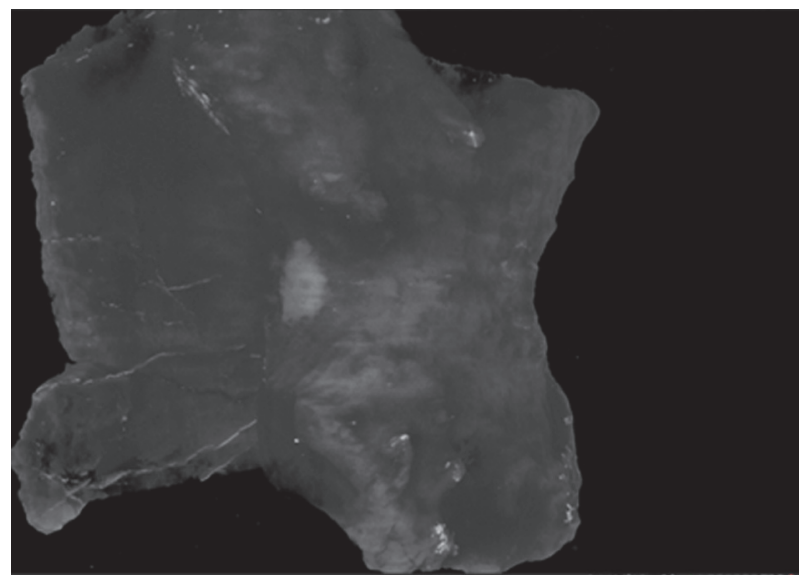

APPENDIX 1.1. Micro CT-scan of Alierasaurus phalanx (in the right foreground) and rib (background on the left). Silver color indicates the thin metal plates.

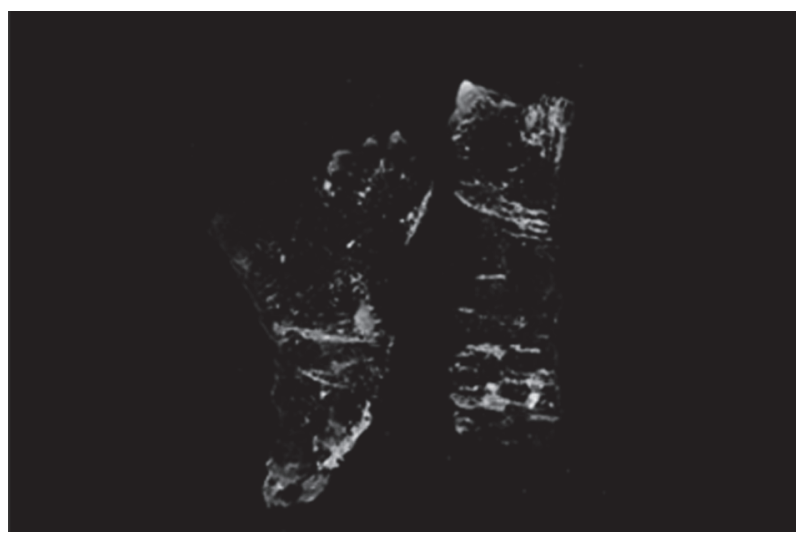

APPENDIX 1.2. Micro CT-scan of Alierasaurus phalanx (on the left) and rib (on the right); gray-light portions indicating the transverse fractures with a diagenetic metallic coating. 


\section{APPENDIX 2.}

New morphometric characters considered in the analysis including Alierasaurus ronchii Specimens directly analyzed: Alierasaurus ronchii (MPUR NS 151), Casea broilii (FMNH UC 656), 'Casea' nicholsi (FMNH UR 86), Cotylorhynchus bransoni (FMNH UR 988), Cotylorhynchus romeri (OMNH 605).

Specimens taken from literature: Angelosaurus dolani (Olson, 1968, p. 262, fig. 18), Captorhinus aguti (Holmes, 2003, p. 520, fig. 7), Diadectes (Berman and Henrici, 2003, p. 178, fig. 3), Dimetrodon milleri (Reisz, 1986, p. 55, fig. 33), Ennatosaurus tecton (Olson, 1968, p. 262, fig. 18), Euromycter rutenus (Sigogneau-Russell and Russell, 1974, p. 189, fig. 18), Ophiacodon retroversus (Reisz, 1986, p. 55, fig. 33) Sphenacodon ferox (Henrici et al., 2005, p. 108, fig. 2), Varanops brevirostris (Reisz, 1986, p. 55, fig. 33), Limnoscelis paludis (Williston, 1911, p.43, fig. 16),

In the case of Euromycter rutenus the foot is not preserved in the holotype, then the hand was used for the construction of ratios. This under the assumption that there are no major differences in metapodials and proximal phalanges between front and hind autopods in non-therapsid synapsids.

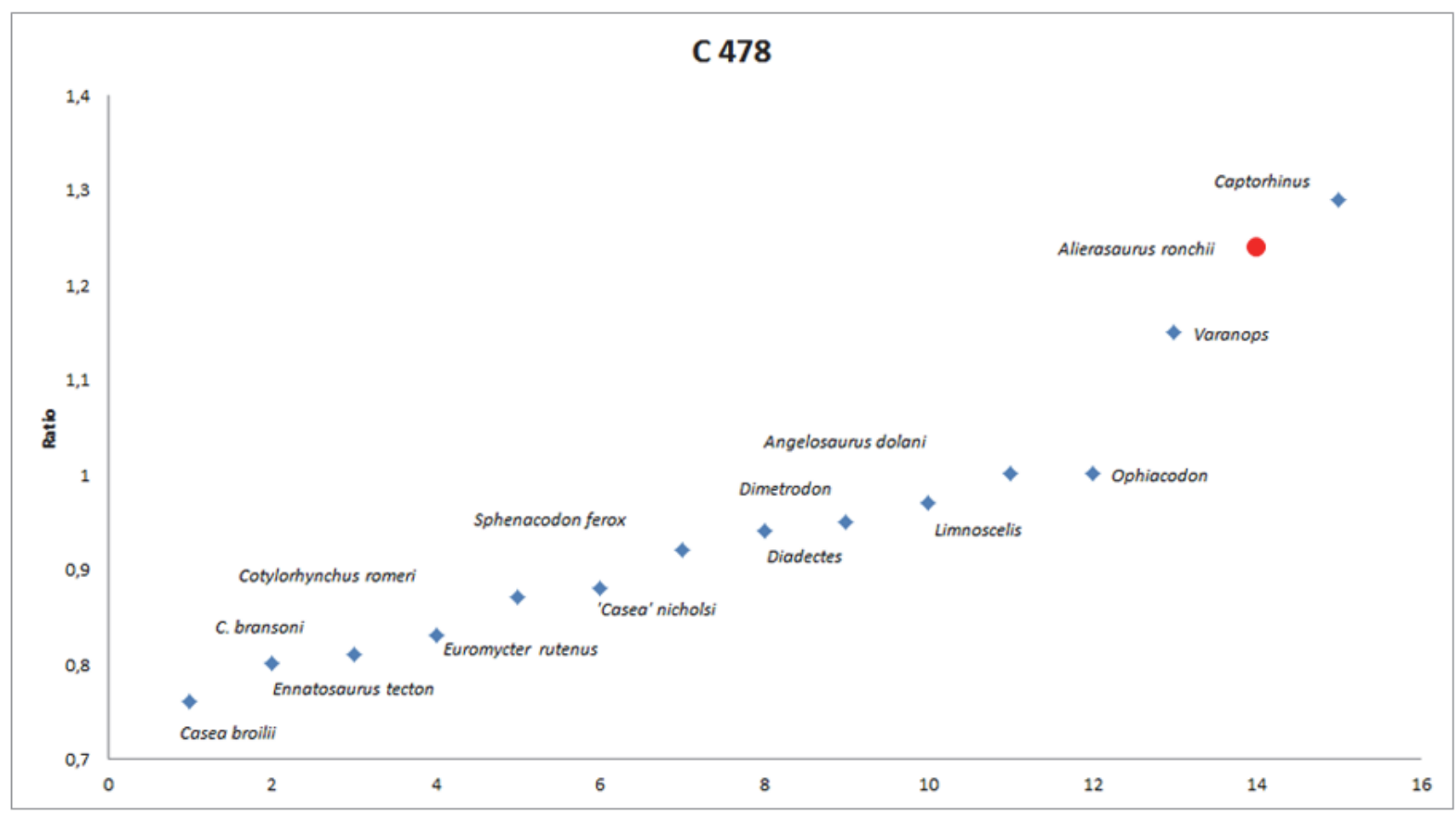

Character 478: Ratio MT-IV proximal width/MT-IV distal width 


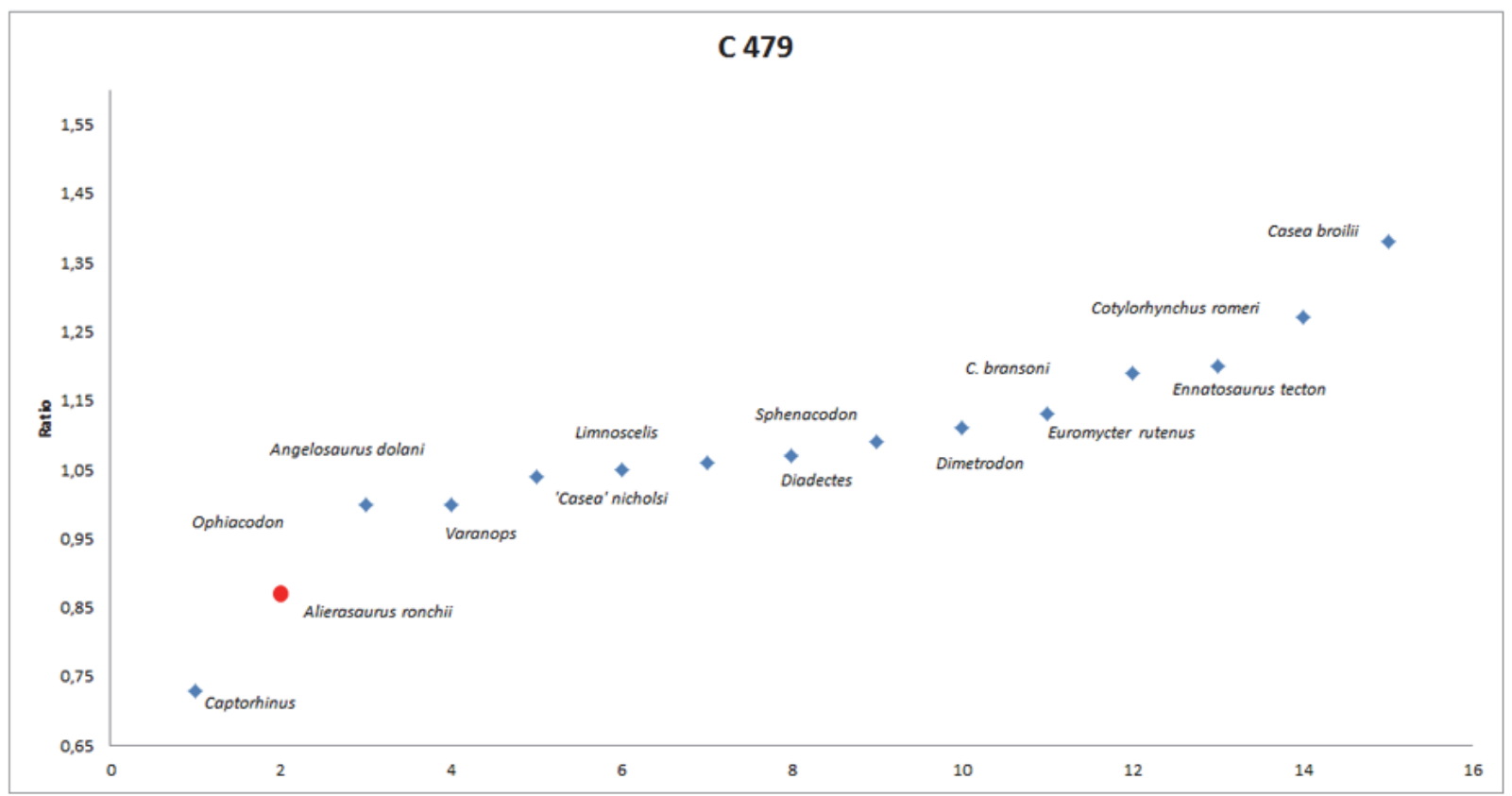

Character 479: Ratio phalanx IV-I proximal width/MT-IV proximal width

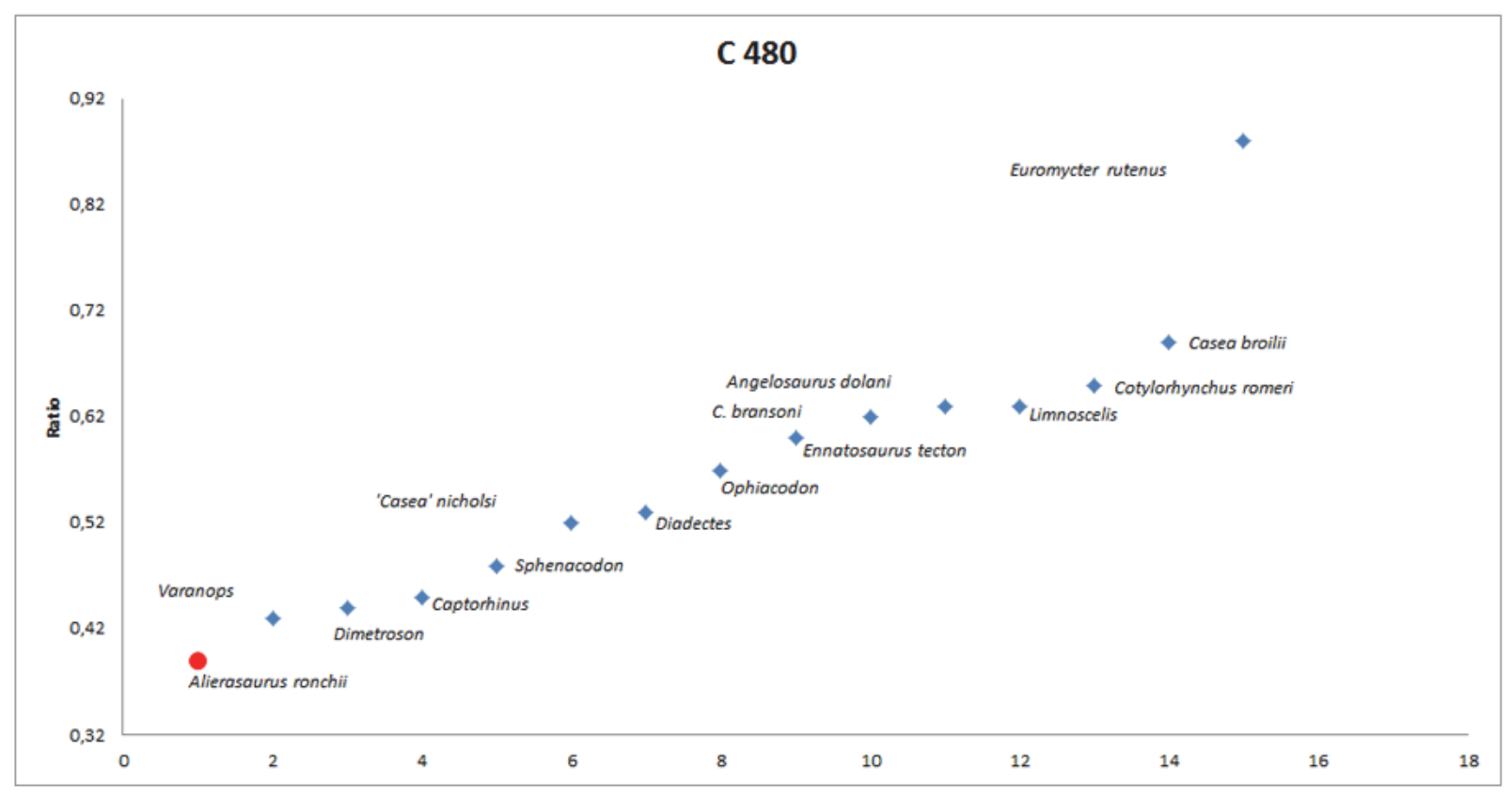

Character 480: Ratio MT-shaft narrowing/MT-IV proximal width 
Romano et al.: NeW material of Alierasaurus

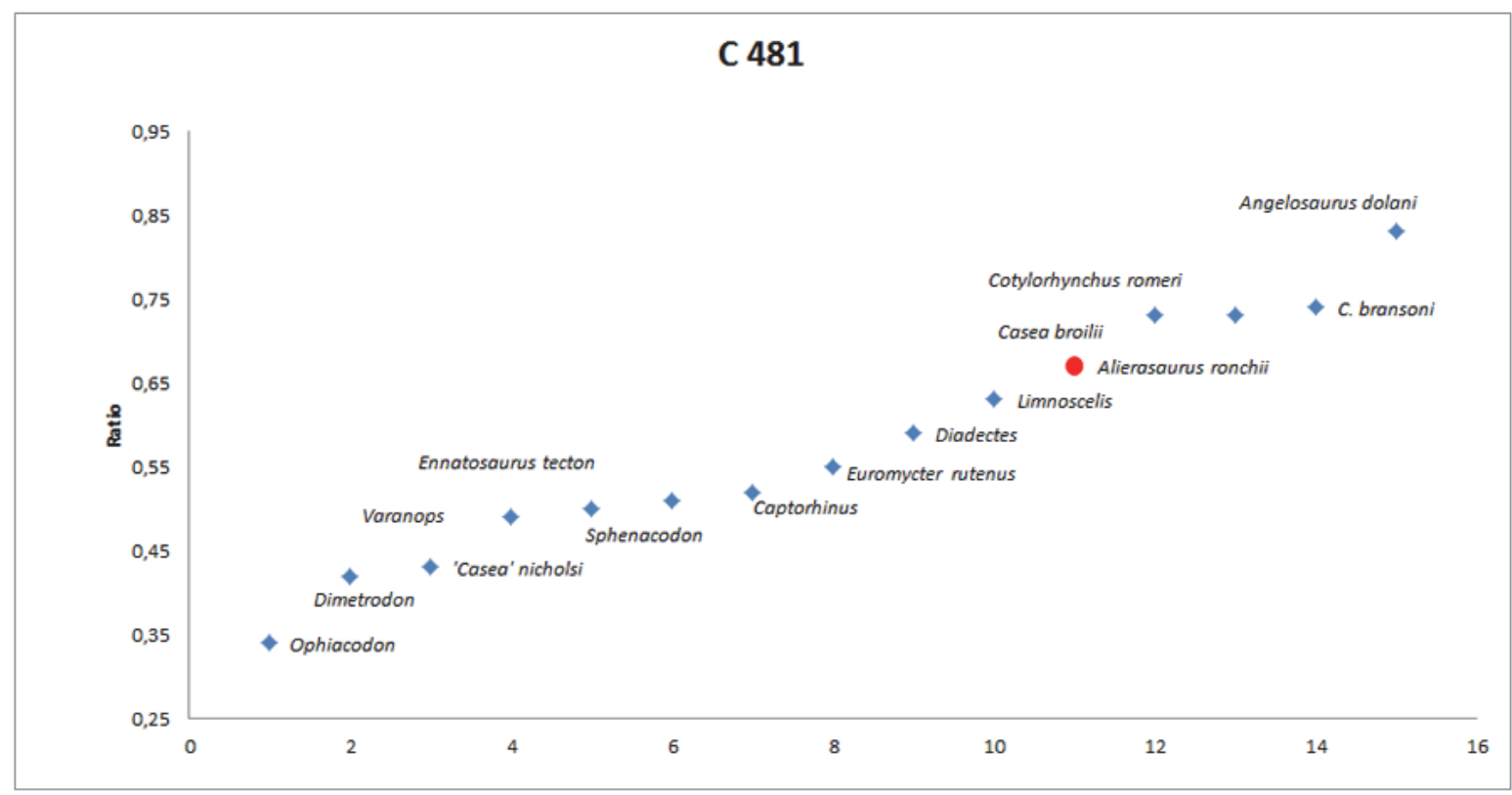

Character 481: Ratio phalanx IV-I total length/MT-IV total length

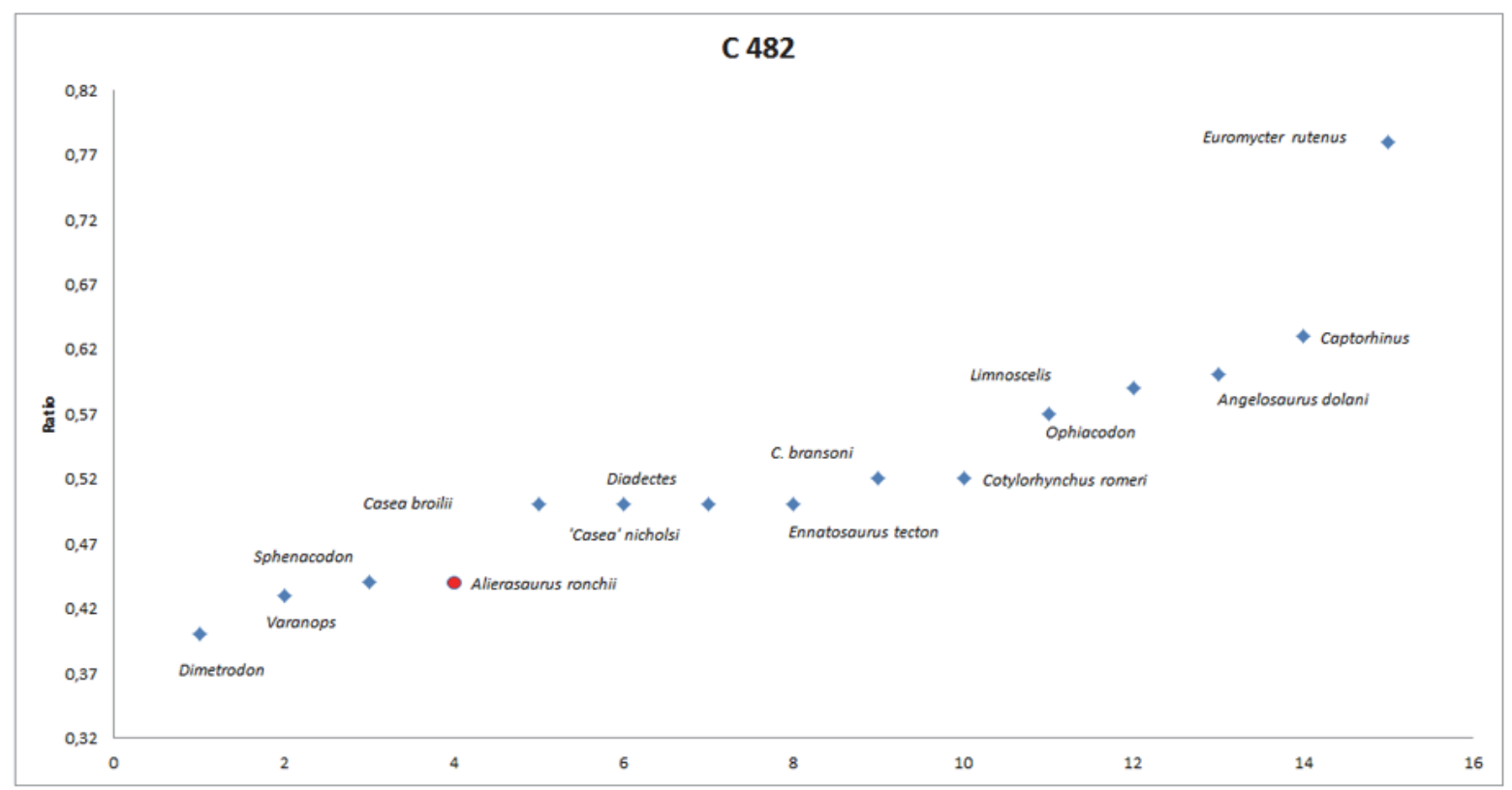

Character 482: Ratio MT-shaft narrowing/phalanx IV-I proximal width 


\section{APPENDIX 3.}

Matrix including Alierasaurus ronchii. See palaeo-electronica.org/content/2017/1889-new-material-of-alierasaurus for zipped file holding NEX file.

\section{APPENDIX 4.}

Matrix including Alierasaurus ronchii and Eocasea martini. See palaeo-electronica.org/content/ 2017/1889-new-material-of-alierasaurus for zipped file holding NEX file. 